\title{
Review of defects in lattice structures manufactured by powder bed fusion
}

\author{
Ifeanyichukwu Echeta ${ }^{1,2} \cdot$ Xiaobing Feng $^{3} \cdot$ Ben Dutton $^{4} \cdot$ Richard Leach $^{1} \cdot$ Samanta Piano $^{1}$ \\ Received: 13 September 2019 / Accepted: 25 November 2019 / Published online: 30 December 2019 \\ (C) The Author(s) 2019
}

\begin{abstract}
Additively manufactured lattice structures are popular due to their desirable properties, such as high specific stiffness and high surface area, and are being explored for several applications including aerospace components, heat exchangers and biomedical implants. The complexity of lattices challenges the fabrication limits of additive manufacturing processes and thus, lattices are particularly prone to manufacturing defects. This paper presents a review of defects in lattice structures produced by powder bed fusion processes. The review focuses on the effects of lattice design on dimensional inaccuracies, surface texture and porosity. The design constraints on lattice structures are also reviewed, as these can help to discourage defect formation. Appropriate process parameters, post-processing techniques and measurement methods are also discussed. The information presented in this paper contributes towards a deeper understanding of defects in lattice structures, aiming to improve the quality and performance of future designs.
\end{abstract}

Keywords Lattice structures $\cdot$ Manufacturing defects $\cdot$ Additive manufacturing $\cdot$ Powder bed fusion

\section{Introduction}

Cellular solids are defined by Gibson and Ashby as 'an interconnected network of solid struts or plates which form the edges and faces of cells' [1]. Cellular solids can take either stochastic or non-stochastic forms, depending on the arrangement of their unit cells. A stochastic design, often called a foam, is controlled globally, often through the manufacturing process, for example, introduction of a gas into a molten material [2]. Stochastic designs, therefore, have high local variability, and the design is controlled only at the macroscale. Non-stochastic arrangements,

Ifeanyichukwu Echeta

Ifeanyi.Echeta@nottingham.ac.uk

1 Manufacturing Metrology Team, Faculty of Engineering, University of Nottingham, Nottingham NG8 1BB, UK

2 Centre for Additive Manufacturing, Faculty of Engineering, University of Nottingham, Nottingham NG8 1BB, UK

3 State Key Laboratory of Mechanical System and Vibration, School of Mechanical Engineering, Shanghai Jiao Tong University, Shanghai, China

4 The Manufacturing Technology Centre Ltd, Ansty Park, Coventry CV7 9JU, UK however, often called lattice structures, are highly ordered; full control over individual unit cells allows for greater control of the structure's properties.

Cellular solids possess a range of desirable properties, such as high specific strength and stiffness, and high surface area to volume ratio [3], and exist in a large number of forms. Examples can often be observed in nature, for example the structure of wood (Fig. 1a), cork and trabecular bone. Nonstochastic examples include the highly ordered arrangements in the atomic structures of crystalline materials. Macroscale examples include truss structures in cranes, bridges (Fig. 1b) and roofing. Between these two scales, so-called mesoscale cellular solids have unit cell sizes ranging from approximately $0.1 \mathrm{~mm}$ to $10 \mathrm{~mm}[4,5]$ (Fig. 1c, d).

Recent developments in additive manufacturing (AM) processes, particularly powder bed fusion (PBF), have seen the number of applications for cellular solids rise in a number of disciplines. Engineering applications include heat exchangers [6-9], which exploit the high surface area to volume ratio to maximise heat transfer, and sandwich structures for aerospace applications, which require lightweight, high-strength materials $[10,11]$. There is also significant interest from the biomedical field, where biocompatible materials are used to develop cellular solids imitating bone tissue, thus enabling the development of bespoke biomedical implants [12-17]. 
Fig. 1 Examples of cellular solids: a scanning electron microscopy image of cork from the bark of Quercus cerris var. cerris [19], b a crane (upper) and a bridge (lower) showing examples of truss structures [20], c, d cellular solids produced by powder bed fusion processes: c non-stochastic AlSi10Mg body centred cubic structure [21], d stochastic Ti6Al4V structure [22]

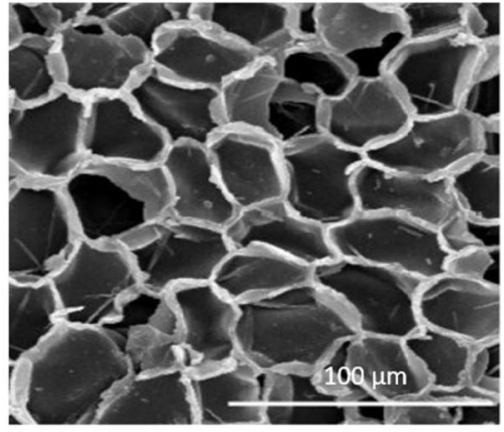

(a)

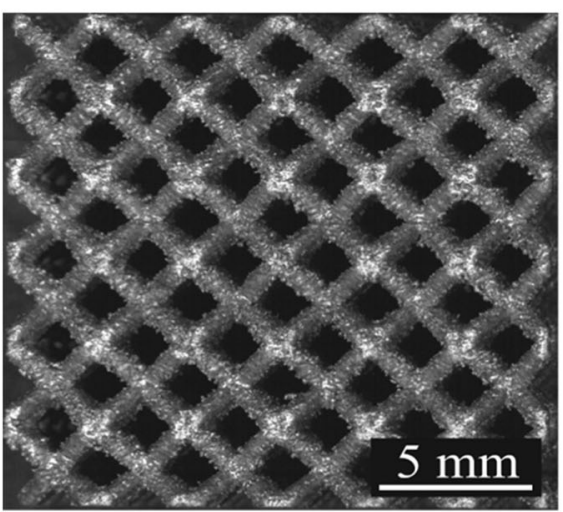

(c)
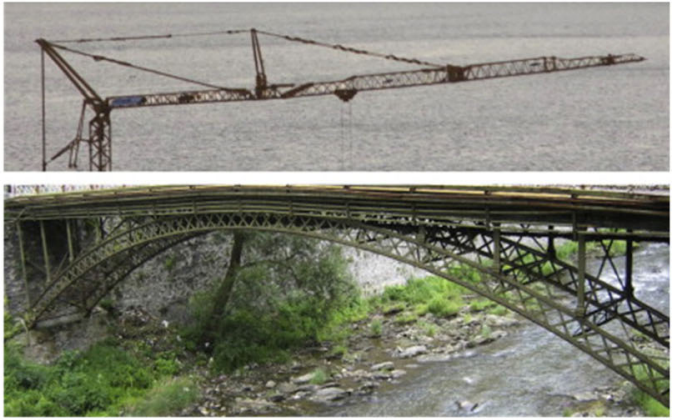

(b)

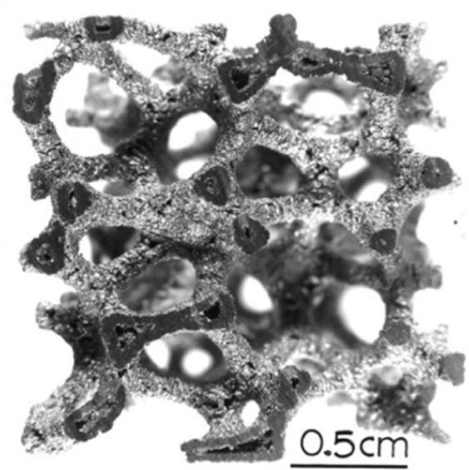

(d)
Cellular solids produced by PBF processes are prone to defects, due to their numerous overhanging, often millimetre-scale features, which challenge the performance limits of PBF systems. Support structures are required to dissipate heat and support overhanging features, however, in PBF, cellular solids prevent the use of support structures as post-manufacture removal is impractical. Therefore, metallic cellular solids produced by PBF are particularly plagued by defects due to higher processing temperatures. Manufacturing defects, that is any measurable deviations between an initial design and the manufactured product, can significantly hinder the desired operating performance of AM parts, for example through the introduction of stress concentrations causing a reduction in fatigue strength [18]. Therefore, particularly considering the load-bearing applications of AM cellular solids, a thorough understanding of manufacturing defects is required and is presented in this review.

\subsection{Contents of the review}

This review paper is focused on the literature regarding manufacturing defects in non-stochastic, metallic, cellular solids produced by PBF, which will hereafter only be referred to as lattice structures. Additionally, only mesoscale lattice structures will be reviewed. Such a scope is justified due to the prevalence of these structures in the literature related to stochastic and/or polymeric forms and alternative manufacturing methods. Mesoscale lattice structures are well suited for the feature resolution of PBF systems and the control afforded to the designer yields a greater range of applications, as reflected in the introduction. Helou and Kara [23] showed laser melting to be the most common technique for lattice structure manufacture, reviewing literature between 1999 and 2016, with Ti6Al4V and 316L stainless steel the two most common materials. Furthermore, searching keywords on Scopus such as 'lattice structure', 'stochastic', 'additive manufacturing', 'laser melting' and taking from the most recent results in 2019 showed $85 \%$ (of 13 results) were related to non-stochastic lattice structures. Additionally, the most cited papers on lattice structures for additive manufacturing also consistently focus on non-stochastic metallic forms (for example, [24-26]).

There are existing reviews in the field of cellular solids which focus on reporting their design, analysis and manufacturing methods $[2,4,23]$. This paper considers defect formation from the perspective of lattice design, as opposed to process control, which is the focus of other AM reviews, such as $[18,27,28]$. To refine the discussion on lattice structure defects, several questions were posed, as shown below.

1. How do defects form in powder bed fusion processes?

2. What type of defects form in lattice structures? 
3. How can defects be appropriately measured in lattice structures?

4. How can defect formation in lattice structures be minimised?

Firstly, an introduction to lattice structures is provided in Sect. 2, and the terminology used in this review is established. Subsequent sections aim to address the above questions, where Sect. 3 provides a description of the PBF process and a brief summary of some existing reviews on general defect formation mechanisms. Section 4 discusses the defects which have been observed specifically in lattice structures, followed by measurement methods for quality inspection and defect mitigation in Sects. 5 and 6 , respectively. To close the review, a summary of the findings is provided along with suggestions on potential future directions. Addressing the above questions aims to offer a well-rounded literature search by providing not just a description of defects in lattice structures but also detailing how the quality of lattice structures has been improved and inspected more appropriately.

This literature review was performed using the main scientific databases (Scopus, Google Scholar) with publication dates ranging from 1994 to 2019. Papers were selected if the contents of the study contributed towards answering any of the above questions.

\section{Lattice structures}

Lattice structure designs are defined by their unit cell, which often falls into one of two categories: strut and surface based (Fig. 2). Strut-based unit cells consist of a network of often prismatic struts (i.e. constant cross section) connected at nodes, similar to truss structures. Surface-based unit cells are mathematically defined as the surface connecting set of points for which a given function has a constant value, that is, an isosurface.

Unit cell design holds large influence over the mechanical properties of a lattice structure. In strut-based unit cells, the connectivity of the struts, that is the number of struts connected at a given node, greatly controls the structure's behaviour under compressive load. For low or high connectivity, unit cells exhibit what is known as bending- or stretch-dominated behaviour, respectively. Bending-dominated structures are desired for applications where mechanical energy absorption is required. Stretch-dominated unit cells are preferred for structural applications, due to greater stiffness and yield strength [29]. Common examples of strut-based lattices are the body- (BCC) and face-centred cubic (FCC) structures (Fig. $2 \mathrm{a}, \mathrm{b})$ which are bending and stretch dominated, respectively.

The most common types of surface-based unit cells are the triply periodic minimal surfaces (TPMS), which have a mean curvature of zero. An example of a surface-based unit cell is the gyroid, developed by Schoen [30] (Fig. 2c, d). The gyroid is defined by the isosurface $\phi$ in three dimensions $(x, y, z)$ :

$\phi=\cos (x) \sin (y)+\cos (y) \sin (z)+\cos (z) \sin (x)=0$.

TPMS unit cells can be further distinguished between those with isosurfaces that have been thickened (sheet/matrix-TPMS), or their enclosed volume solidified (skeletal/network-TPMS), as shown in Fig. 2c, d. Some skeletal/network TPMS designs appear to possess strut-like features, as is the case for the skeletal gyroid (Fig. 2c). The user has less design control with TPMS unit cells, however they are currently studied for applications such as biomedical implants [12]. Additionally, there are custom designs outside of strut-based and surface-based forms, for example those produced using topology optimisation [31] and with internal resonators for vibration isolation [32].

A key property of a unit cell is its relative density, which is defined as the ratio of the density of the unit cell to that of the comprising material [1]. Therefore, the density of the unit cell, often called volume fraction (see Table 1), is a design feature of key importance, largely controlling the mechanical properties of the structure. Additional terms for lattice design features are listed in Table 1. Some definitions are described in the literature using different terms, for example volume fraction can be referred to as 'porosity', particularly in biomedical applications where the designed void space in a unit cell is required for bone ingrowth. Therefore, for consistency in this review, the terms in Table 1 will be adhered to. Note that Table 1 is not an exhaustive list, and the references serve only as examples of where such terms can be found within the papers in this review.
Fig. 2 Types of unit cells: a bodycentred cubic, $\mathbf{b}$ face-centred cubic, $\mathbf{c}$ gyroid (skeletal/network) and double gyroid (sheet/ matrix) [33]

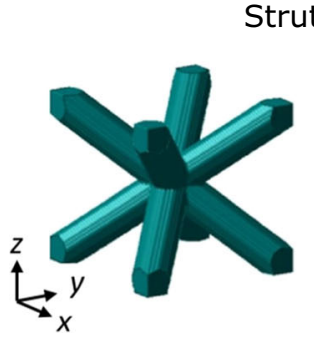

(a)
Strut-based

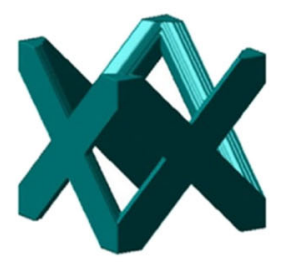

(b)

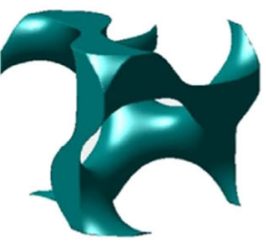

(c)
Surface-based

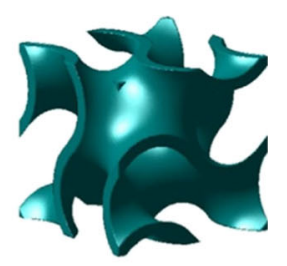

(d) 
Table 1 Lattice terminology

\begin{tabular}{|c|c|c|}
\hline Terminology in this paper & Definition & Alternative terms in literature \\
\hline Lattice structure & Mesoscale, non-stochastic, cellular solid & $\begin{array}{l}\text { Porous structure }[34,35] \text {, microlattice }[5,9] \text {, scaffold } \\
\quad[16,36]\end{array}$ \\
\hline Periodicity & Unit cell tessellations in $(x, y, z)$ & Staggering [37] \\
\hline Node & $\begin{array}{l}\text { The intersection of multiple struts (or strut-like } \\
\text { features, in the case of some surface-based cells) }\end{array}$ & Strut junction $[38,39]$, truss corners $[40]$ \\
\hline Volume fraction & $\begin{array}{l}\text { Ratio between the volume of material in the unit cell } \\
\text { and its bounding box (often expressed as a percentage) }\end{array}$ & Porosity [41, 42], solid fraction [43] \\
\hline Pore/porosity & $\begin{array}{l}\text { Unintentional void within the lattice structure/ratio of pore } \\
\text { volume to material volume }\end{array}$ & $\mathrm{n} / \mathrm{a}^{\mathrm{a}}$ \\
\hline $\begin{array}{l}\text { Designed pore/designed } \\
\text { porosity }\end{array}$ & $\begin{array}{l}\text { Void space included in the unit cell design/ratio of designed } \\
\text { pore volume to material volume (i.e. the complement of volume } \\
\text { fraction) }\end{array}$ & Pore/porosity $[36,42]$ \\
\hline
\end{tabular}

${ }^{\mathrm{a}}$ No alternative terms found from the papers in this review

\section{Powder bed fusion}

PBF operates by using focused thermal energy to selectively fuse regions of a powder bed [44], with potential to create highly intricate geometries, with millimetre scale features. Figure 3 is a schema of the PBF process, which can be summarised in the following steps. A layer of powder (typically of thickness $20 \mu \mathrm{m}$ to $150 \mu \mathrm{m})$ is spread across the build bed. A thermal energy source is focused onto the powder bed and fuses the predefined regions. The part is then lowered by onelayer thickness and the process repeats until completion. Within PBF, there are three main processes which share this operating procedure: laser sintering (LS), laser melting (LM) and electron beam melting (EBM). Laser sintering is used to process polymer powders while laser melting and electron beam melting process metal powder. The main difference between polymer and metal processing is in the input energy, where higher energies are required to produce full melting for metal powders. LM and EBM differ fundamentally in energy source, and this difference yields several effects, such as a reduced feature resolution in EBM due to defocusing of the beam to prevent a build-up of negative charge [45]. Within metal PBF processes, support structures are often required to attach the part to the build bed in order to prevent distortion from residual stresses induced through high thermal gradients and to support overhanging features that would otherwise distort under gravity [45].

PBF process parameters can be grouped into four categories [45]: thermal source parameters, scan parameters, powder parameters and temperature-related parameters. The thermal source parameters, such as laser power, most directly control the fusing of powder material and, in the case of full melting, directly affect the melt pool characteristics. Scan parameters control the manner in which material is fused, for example scan speed and scanning patterns which can control surface finish. Powder parameters such as powder size and layer thickness can control the absorption characteristics of the powder bed and the thickness of each layer. Temperature related parameters, such as powder bed temperature, have a strong influence on the repeatability of the manufacturing process, where constant temperatures encourage uniformity throughout the build bed and between batches of production.

The term energy density $E D$ defines the relationship between primary process parameters and provides a useful means for selecting optimal processing parameters. $E D$ is defined as:
Fig. 3 Schema of the powder bed fusion process

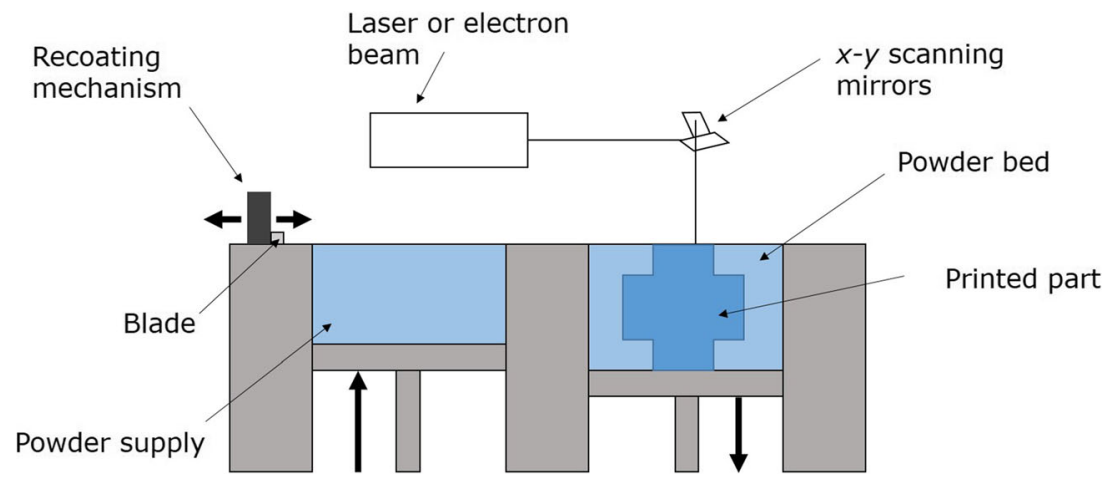




$$
E D=\frac{P}{v h t},
$$

where $P$ is laser power, $v$ is scan speed, $h$ is hatch spacing (the spacing between scanning paths) and $t$ is layer thickness [46]. These parameters are often used to investigate the effects of process parameters on print quality (for example, $[47,48]$ ).

\subsection{Defect formation mechanisms}

This section provides a brief background on the defects commonly formed in PBF processes, providing useful context to the following sections which discuss defects found specifically in lattice structures. The heating, melting and cooling mechanisms within the powder bed are at the core of the final quality of the parts produced by PBF and are discussed within several review papers on defects in PBF processes. From [18, 27, 49], three main categories of defects were identified: porosity/incomplete fusion, residual stresses and surface defects.

Porosity is defined by Zhang et al. [27] as approximately spherical voids with diameter typically less than $100 \mu \mathrm{m}$ (Fig. $4 a)$. Pores can form when gases within the melt pool are entrapped due to high cooling rates (up to $10^{8} \mathrm{~K} / \mathrm{s}$ ). The entrapped gases initially form either from gaps within the powder bed or through evaporation of lower melting point constituents within the powder material. Pores can also form through the use of hollow powder particles and through ridges formed in previous layers which impede the flow of the melt pool. Incomplete fusion defects are explained by Zhang et al. [27] to occur mainly due to insufficient input energy and thus often form as irregular voids containing un-melted powders (Fig. 4b). Incomplete fusion defects can form through consecutive layers, again as melt pool flow is impeded. For easily oxidised materials, (for example AlSil0Mg) the formation of oxide layers reduces wettability, which also impedes melt pool flow and causes additional incomplete fusion.

Residual stresses are formed through PBF processes due to the high thermal gradients and cooling rates within the powder bed subjecting the part to rapid expansion and contraction. Residual stresses can cause cracks to form [27], delamination between layers [18] (Fig. 4c) and dimensional inaccuracies through shrinkage or warping [18]. Cracking is more likely to occur in materials such as stainless steels and nickel-based superalloys, due to their low thermal conductivity and high coefficient of thermal expansion [27]. Mercelis and Kruth [50] define two mechanisms through which residual stresses are induced. Firstly, the temperature gradient mechanism, where upon heating the part, expansion is hindered by the solidified material beneath, creating compressive residual stresses. Secondly, upon cooling of molten layers, contraction is hindered, creating tensile residual stresses. Mercelis and
Kruth note that the temperature gradient mechanism does not require the material to be molten and can, therefore, occur in both LS and LM, whereas the cooling mechanism within the melt pool only occurs in LM.

Highly complex surfaces are produced in PBF processes where the interaction between the powder material and energy source forms a number of surface irregularities. Unstable melt pools can cause balling and spatter. Balling occurs when the melt pool solidifies into a sphere instead of wetting the underlying substrate to form a layermainly controlled by the length-to-width ratio of the melt pool, where a ratio less than 2.1 is desirable [49] (Fig. 4d). Spatter occurs at higher energy densities, where molten material is expulsed by the recoil pressure generated by evaporation within the melt pool (Fig. 4e). Inter-layer surface defects are also present, where discontinuities form between successive layers, i.e. stair stepping. The orientation of a surface further affects the quality. Surfaces whose normal is directed towards the build bed (called down-skin surfaces) produce significantly more irregular surfaces than those whose normal faces away (i.e. up-skin). This discrepancy is due to the support powder, which is a poor conductor of heat. Therefore, down-skin surfaces experience excess heating and poor cooling through support powder, whereas up-skin surfaces cool faster via conduction through the solidified part underneath [18].

\section{Lattice structure defects}

This section follows on from the previous discussion of defect formation and aims to establish the types of defects that form specifically in lattice structures, with a focus on how design features influence defect formation. In the literature, lattice structure defects are frequently categorised into the following groups: dimensional inaccuracies, surface texture and porosity. Dimensional inaccuracies occur on the same scale as the lattice features, for example a deviation in the length or overall volume. Surface defects refer to any deviation from the ideal surface and are often quantified using surface texture parameters, providing a quantitative description of surface texture. Porosity denotes the absence of material, where a pore describes a closed void within the part, or a surface void. When necessary, measurement methods will be mentioned to provide context, and will be covered in more detail in Sect. 5.1.

\subsection{Dimensional inaccuracies}

It is often helpful to first globally assess a lattice structure's general conformity to CAD data, as performed by $[31,36$, 56-58], where the results generally show a reasonable adherence to CAD data. However, dimensional inaccuracies can be 


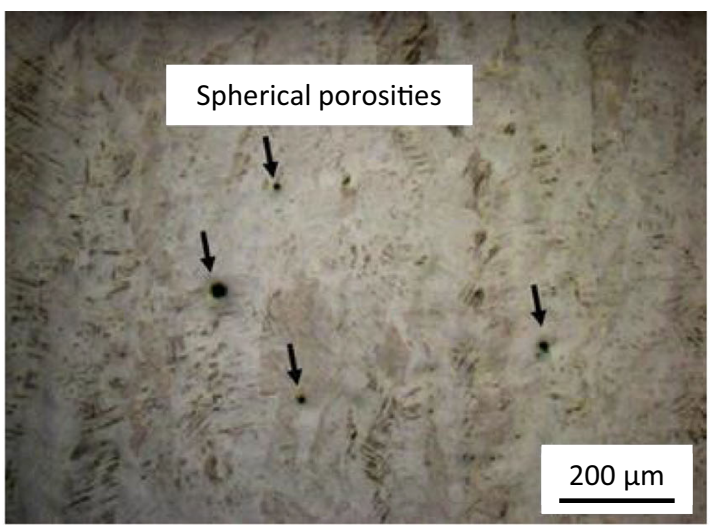

(a)

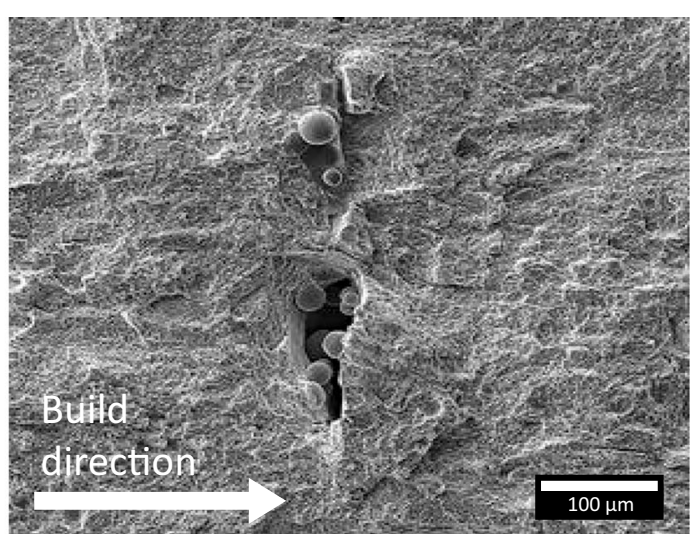

(b)

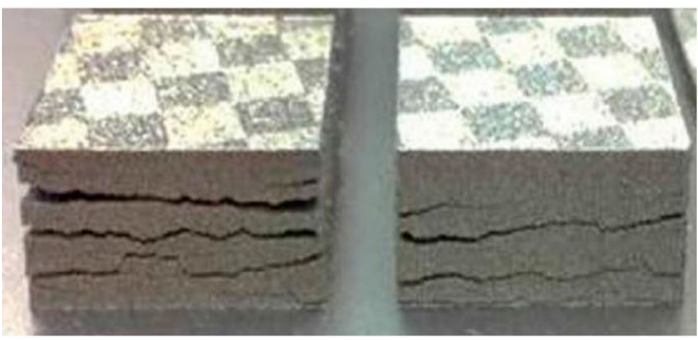

(c)

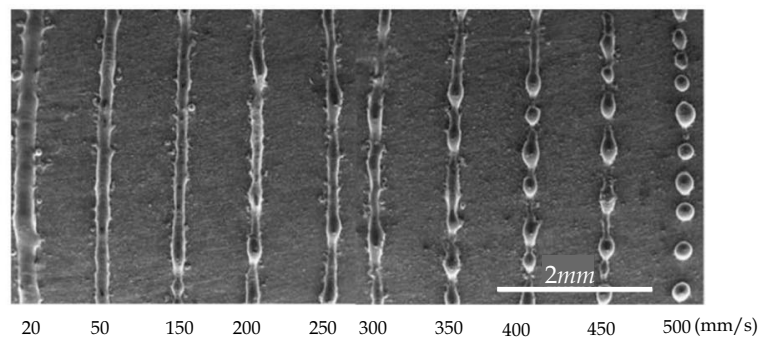

(d)

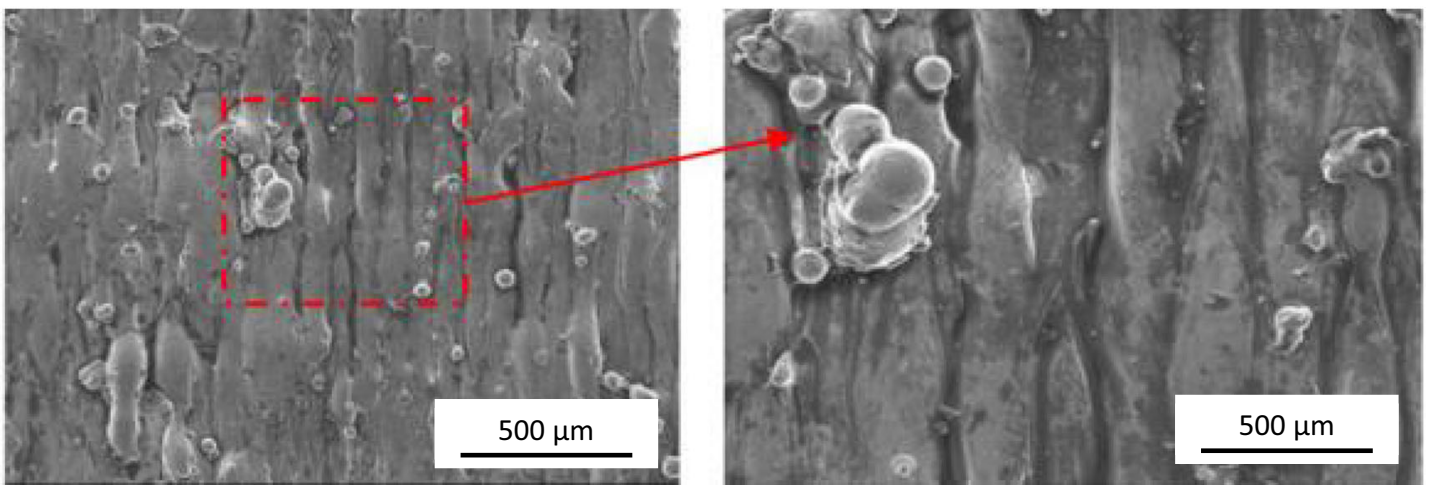

(e)

Fig. 4 Examples of the defects which form in PBF processes: a porosity [51] (annotations from [18]), b incomplete fusion [52], c severe cracking causing delamination [53], d balling occurring at higher scanning speeds [54] and e spatter [55]

better understood via a local analysis of specific lattice features, such as struts, nodes, designed pores and wall thicknesses. Struts have been observed to deviate from circular cross-sections to ellipsoidal in references [59-62]. Ataee et al. [61] particularly note the effect to be strongest at the ends of the struts. Arabnejad et al. [59] observe ellipsoidal deviations to a greater degree in horizontal struts, due to overmelting.

The average diameter of lattice struts has been observed to significantly deviate from the initial design, as shown in Table 2, where both over- and under-sizing have been observed. Cuadrado et al. [63] and Arabnejad et al. [59] show strut diameter to be significantly affected by strut orientation, where vertically oriented struts were under-sized by up to $45 \%$, and horizontal struts were over-sized by over $100 \%$. Cuadrado et al. [63] linked deviations in strut diameter to the overall volume fraction of lattice structures, observing a volume fraction less than designed in lattice structures consisting of a significant portion of vertical struts, with the opposite occurring in designs with more horizontal struts. Zhang et al. observed similar orientation-dependent thickness variations in sheet TPMS unit cells (primitive, diamond, gyroid) [60]. 
Table 2 Deviation in strut diameter

\begin{tabular}{|c|c|c|}
\hline & $\begin{array}{l}\text { Designed strut } \\
\text { diameter }(\mathrm{mm})\end{array}$ & Strut deviation $(\mathrm{mm})$ \\
\hline Sing et al. [74] & 0.6 to 0.8 & -0.5 to $-0.2 ;$ up to $\sim 60 \%$ \\
\hline $\begin{array}{l}\text { Tancogne-Dejean } \\
\text { et al. [71] }\end{array}$ & 0.534 & $\begin{array}{l}\text { Average strut deviation, } \\
\quad-0.01(\sim 2 \%)\end{array}$ \\
\hline Choy et al. [75] & 0.4 to 1.2 & -0.138 to $+0.156(-10 \%$ to $+40 \%)$ \\
\hline $\begin{array}{l}\text { Cuadrado et al. } \\
\text { [63] }\end{array}$ & 0.65 & $\begin{array}{l}\text { Vertical, } 0.46(-30 \%) \\
\text { sloped, } 0.36(-45 \%) \\
\text { horizontal, } 1(+54 \%)\end{array}$ \\
\hline $\begin{array}{l}\text { Arabnejad et al. } \\
\quad[59]\end{array}$ & 0.2 & $\begin{array}{l}\text { Vertical, } 0.11(-45 \%) \\
\text { sloped, } 0.26(+30 \%) \\
\text { horizontal, } 0.45(+128 \%)\end{array}$ \\
\hline
\end{tabular}

Melancon et al. [42] and Liu et al. [64] observed deviations in the position of struts' axes, defining this deviation as 'strut waviness' (Fig. 5a). As with variations in diameter, strut waviness was observed to occur to a greater degree in horizontal struts. Liu et al. calculated an increase in strut waviness from approximately $8 \%$ to $17 \%$ in diagonally oriented struts and horizontal struts, respectively. Melancon et al. also calculated an increase, to a lesser degree, of $7 \%$ to $9 \%$ in diagonal and horizontal struts, respectively. Similar observations on strut orientation dependency are also observed in references [60, 65-67].

The effects of strut orientation dependency are highlighted by Sercombe et al. [43], who found horizontal struts to cause lattice structures to fail under compression, as the horizontal struts carried tensile loads (Fig. 5b).

Several defects have been observed around lattice nodes. Excess material accumulation at nodes has been observed by Gümrük et al. [68]. Similar results were seen by Li et al. [69], where strut diameters increased by approximately $30 \%$ around the nodes (from $0.3 \mathrm{~mm}$ to a maximum of $2 \mathrm{~mm}$ ). Al-Ketan etal. [70] compared several unitcell designs and found nodes to be smoother in surface-based unit cells. Additional comments on nodal distortions are made in references $[71,72]$.

Regarding designed pores, Hollander et al. [73] and Lin et al. [31] both observed material accumulation called 'surface protrusions' (Fig. 5c) - the most severe of these extended across $0.3 \mathrm{~mm}$ (30\%) of the designed pore diameter [73]. Obstructions within designed pores can impede bone ingrowth in lattice structures for biomedical applications.

\subsection{Surface defects}

As previously discussed, highly complex surfaces are produced in PBF processes and surface defects are often formed due to melt pool instabilities. The most prevalent surface defects in lattice structures can be observed when comparing down-skin and up-skin surfaces. Local over-heating in down-skin surfaces is often observed due to the many overhanging features in lattice structures $[16,43,56,69,70,76$, 77]. Surface texture parameters, as defined by ISO 4287 [78], (a)

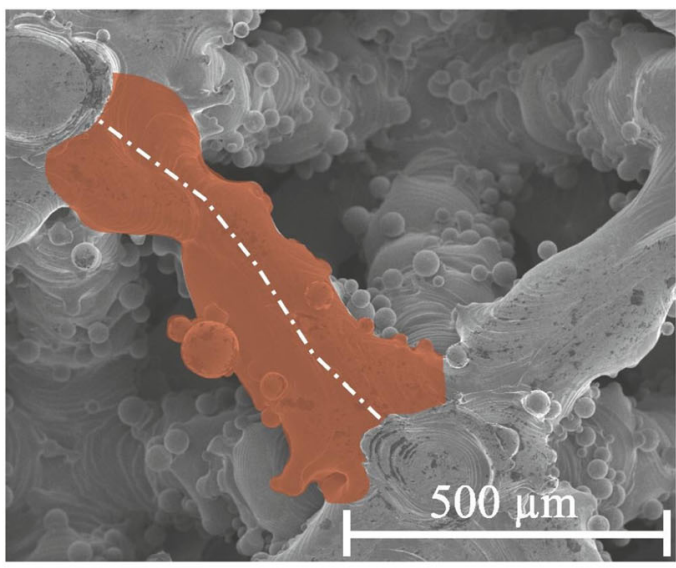

(b)
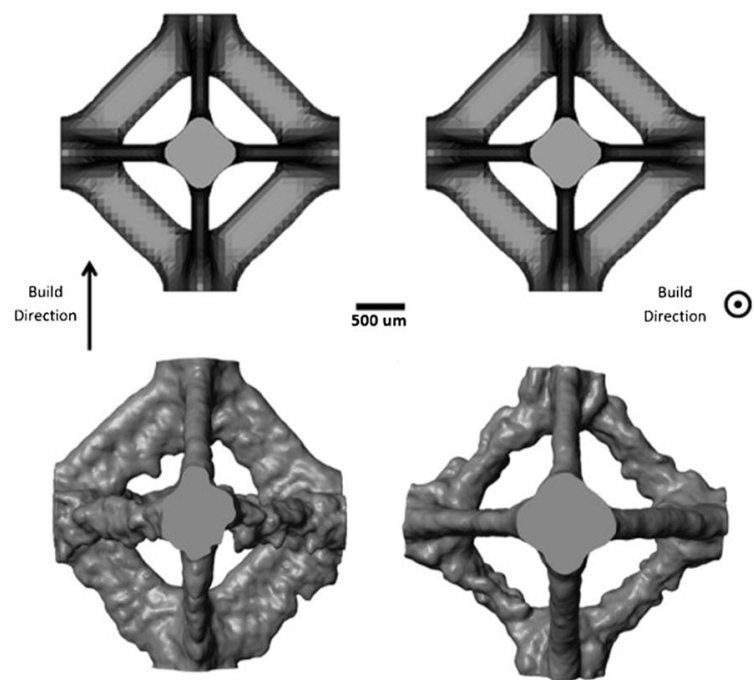

(c)

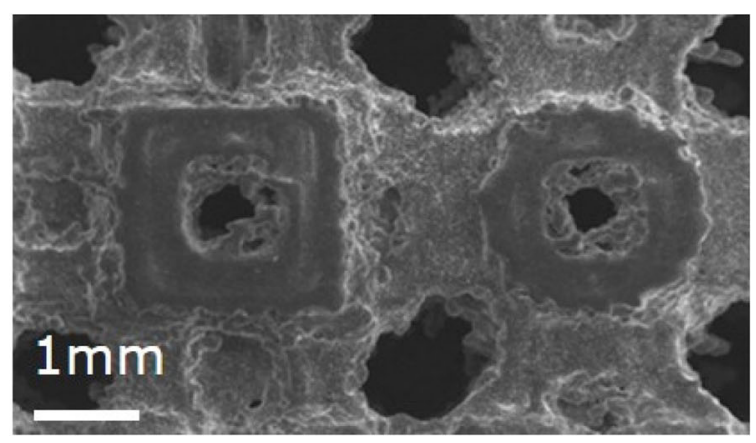

Fig. 5 Examples of dimensional inaccuracies in lattice structures. a An example of strut waviness. SEM micrograph provided by ref. [42]. Varying strut diameter can also be observed. b Example of strut orientationdependency. Top, CAD representation of unit cell. Bottom, 3D rendering of an X-ray computed tomography model. Horizontal struts are shown to be highly irregular [43]. $\mathbf{c}$ Example of surface protrusions in designed pores [31]

have been used by Pyka et al. [79] and Leary et al. [72] to quantitatively analyse up-skin and down-skin lattice structure surfaces, as shown in Table 3. Pyka et al. found the $R a$ value of down-skin surfaces to be approximately twice that of the upskin surface. Leary et al. calculated $R a$ and $R z$ values for downskin and up-skin surfaces in BCC and FCC struts, which have 
Table $3 \quad R a$ values for up-skin and down-skin lattice surfaces

Surface roughness parameter

\begin{tabular}{lll} 
& Up-skin $(\mu \mathrm{m})$ & Down-skin $R a(\mu \mathrm{m})$ \\
\hline Pyka et al. [79] & $R a=8$ & $R a=15$ \\
Leary et al. [72] & $45^{\circ}: R a=8.9$, & $45^{\circ}: R a=43.5 R z=235.5 ;$ \\
& $R z=60.5 ; 35^{\circ}:$ & $35^{\circ}: R a=120.2$, \\
& $R a=8.8, R z=53$ & $R z=456.5$ \\
\hline
\end{tabular}

inclination angles to the build bed of approximately $35^{\circ}$ and $45^{\circ}$, respectively. Leary et al. calculated an $R a$ value of downskin BCC struts to be almost three times that of FCC. The $R z$ values for $\mathrm{BCC}$ down-skin surfaces was also significantly larger than for BCC. The $R a$ values for up-skin and side surfaces showed little variation upon changing orientation.

Al-Ketan [70] compared the surfaces of strut- and surfacebased unit cells, and observed the stair-stepping effect to be less pronounced in surface-based unit cell-an example is shown in Fig. 6. A reduced stair-stepping effect has been attributed to the continuous change in inclination angle in surface-based designs (further discussed in Sect. 6.1). Other supporting comments on the texture of lattice surfaces can be found elsewhere [11, 36, 37, 41, 57, 58, 68, 71, 73, 80-87].

\subsection{Porosity}

Pores are typically referred to as enclosed voids beneath the part's surface, however, more regular, hemispherical voids can be identified as surface pores. Under load, pores form stress concentrations which can have a significant effect on fatigue properties.

Low levels of porosity (approximately 1\%) are achievable in AM processes, as in [88, 89], and as expected, similar results are found among lattice structures $[24,56,57,71,75$, $87,90-92]$. Process parameters are often the focus of the cause of porosity, as in references $[89,93,94]$. In lattice design, however, Yan et al. [24] observed porosity to increase up to approximately $10 \%$ upon increasing the size of gyroid unit cells $(2 \mathrm{~mm}$ to $8 \mathrm{~mm})$. This was attributed to the longer scanning paths required for larger unit cells which allows a greater period of time for pores to form in between adjacent scanning tracksas constant process parameters were used for the different cell sizes. Yan et al. highlight that further optimisation of the parameters depending on unit cell size should alleviate any increase in porosity. Amani et al. [95] also attribute scan strategy to an increase in porosity, where pore size was observed to increase at the nodes of lattices (Fig. 7).

Dong et al. [65] investigated the influence of strut orientation on porosity for AlSi10Mg lattices. Struts were printed at varying inclination angles from the build bed and each strut was partitioned into an upper and lower region (A and B as shown in Fig. 8). The results (Fig. 8) showed overall porosity to increase as inclination angle decreased. Furthermore, pore distribution was significantly skewed as the majority of the pores were located in the lower regions of the struts, with this effect increasing upon decreasing inclination angle. These observations were attributed to the cooling mechanisms, where inclined struts are subject to lower cooling rates due to direct contact with support powder, which yields higher temperatures and thus increases the formation of hydrogen pores. The differences in porosity were reflected in the tensile mechanical properties of the struts, for example a $22 \%$ increase in ultimate tensile strength was observed between struts printed at $35.5^{\circ}$ and $90^{\circ}$. Similar observations were made by Delroisse et al. [96], also for AlSi10Mg struts.

\section{Quality inspection of lattice structures}

This section will cover the methods used to inspect the quality of lattice structures. This will be followed by a discussion on the limitations of these methods and additional considerations to enable more reliable results.

\subsection{Measurement methods}

Table 4 summarises the methods that have been used in the studies discussed in this review to inspect defects in lattice structures. Only quantitative methods will be discussed in
Fig. 6 Left to right, SEM micrograph of two unit cells, skeletal gyroid (surface-based) and Kelvin structure (strut-based). A more pronounced stairstepping effect can be seen in the Kelvin structure [70]
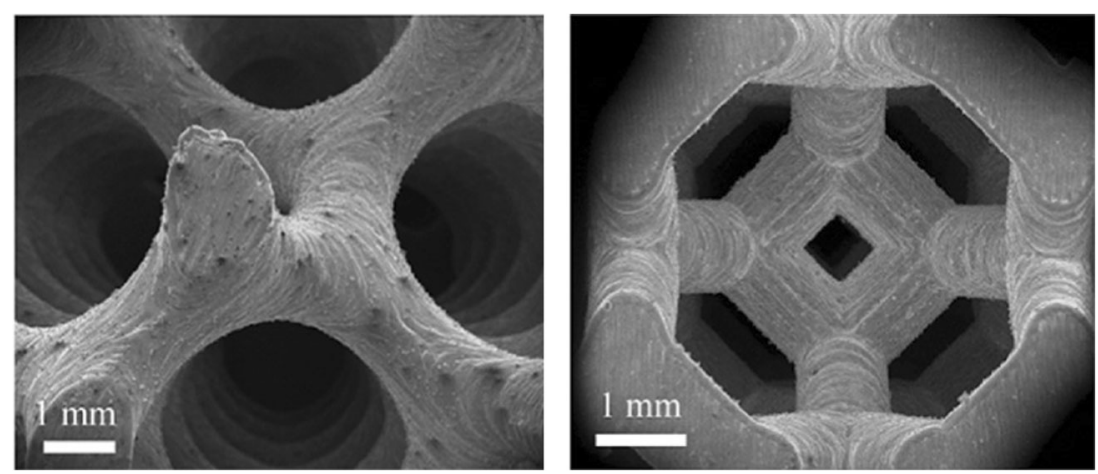


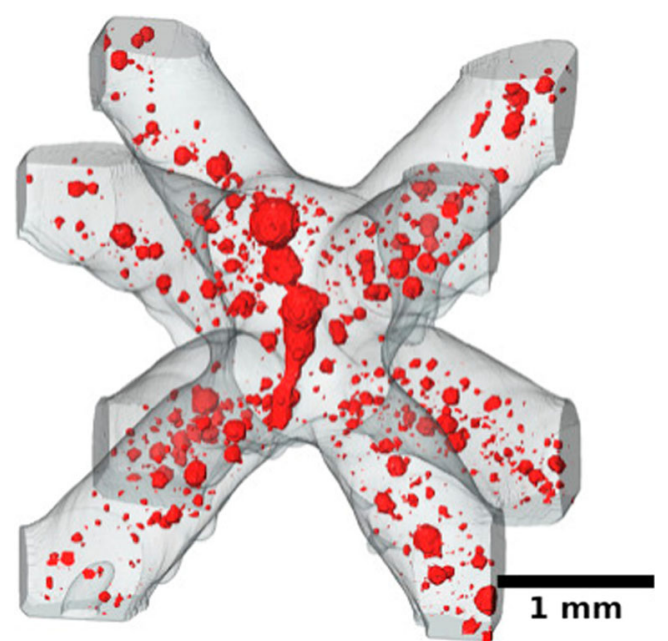

Fig. 7 XCT results from [95] showing increased porosity in the nodes of a lattice

the following section. For additional measurement techniques, a thorough summary is provided by Banhart et al. [2].

\subsubsection{Dimensional inaccuracies}

$\mathrm{X}$-ray computed tomography (XCT) data can be aligned to the original $\mathrm{CAD}$ model for comparison against the nominal values. This alignment can be used to calculate the maximum or average deviation of the XCT data points $[36,56,57]$. Other methods using XCT include measuring the volume or surface area of the lattice structure, as demonstrated by Van Bael et al. [97, 98] and Parthasarathy et al. [58]. For local strut measurements, Qiu et al. [87] and Melancon et al. [42] calculated strut diameter as the largest circle that could be inscribed, using the two-dimensinal data from individual XCT slice images. Pyka et al. [79] and Heinl et al. [82] expand this into three dimensions by using sphere-fitting algorithms to measure the diameters of struts and designed pores. Hrabe et al. [83] suggest that using the median value of inscribed sphere diameter is a more appropriate representation of the strut diameter. Hildebrand and Rüegsegger [99] highlight additional parameters useful for characterising lattice structures with XCT, for example the ratio of surface area to volume which could allow for a comparison of attached particles in multiple samples.

Dimensional measurements have been performed using XCT [98, 100], SEM [11, 13, 68, 69, 73, 85-87, 101-103] and optical microscopy $[25,36,63,75,76,104-106]$. It is also relatively common to use Vernier callipers for the measurement of outer dimensions (for example, lattice diameter, length, width) $[74,103,104,107]$. The lattice's mass has been used to calculate volume fraction, as performed by Al-Ketan et al. [70] and Wieding et al. [108].

\subsubsection{Surface texture}

$R a$ values from profiles of strut surfaces have been calculated using XCT, by Kerckhofs et al. [77], Pyka et al. [79], and de Formanoir et al. [109], and using optical microscopy by Leary et al. [72]. Similarly, $R a$ was determined using the variation in strut cross-sectional area using XCT by Tancogne-Dejean et al. [71].

\subsubsection{Porosity}

Archimedes' principle is often used to calculate porosity by comparing the mass of a lattice in two different fluids [24, 57, $75,92]$. XCT has been used to calculate porosity $[56,65,95$, 96]. Amani et al. [95] employ a stitching method with XCT, whereby small portions of the lattice are imaged at higher magnification and are stitched together. This enabled smaller voxel sizes to be achieved and a greater proportion of pores were detected. Optical microscopy was used by Qiu et al. [87] and Köhnen et al. [90] to calculate an average porosity from a
Fig. 8 Results from Dong et al. [65] showing the effects of strut inclination on porosity in AlSi10Mg lattice struts. (This graph was developed from the tabulated results and is not from the original paper. Inset illustration of strut partitioning (top right) was taken directly from the paper)

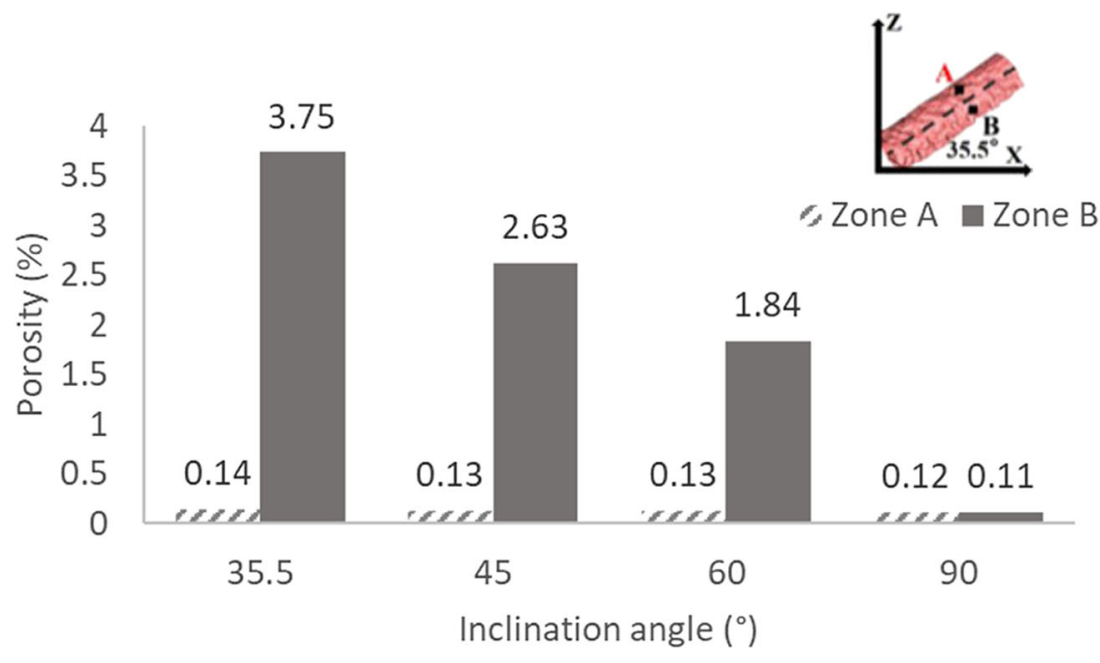


Table 4 Defect measurement methods

\begin{tabular}{|c|c|c|c|}
\hline Defect & Method & Reference & Quantitative characterising techniques \\
\hline \multirow[t]{4}{*}{$\begin{array}{l}\text { Dimensional } \\
\text { inaccuracies }\end{array}$} & $\mathrm{XCT}$ & $\begin{array}{l}{[31,36,42,43,56-59,62,64,71,72} \\
\quad 79,82,83,87,95,97,98,100,110,111]\end{array}$ & $\begin{array}{l}\text { - Comparison with CAD. Maximum or average } \\
\text { deviation } \\
\text { - Calculate total volume } \\
\text { - Measure strut diameter (largest circle/sphere inscribed) } \\
\text { - Elliptical strut cross-section }\end{array}$ \\
\hline & $\begin{array}{l}\text { SEM } \\
\text { Optical microscopy }\end{array}$ & $\begin{array}{l}{[11,13,68,69,73,85-87,101-103]} \\
{[25,36,63,75,76,104-106]}\end{array}$ & Dimensional measurements (length, diameter etc.) \\
\hline & Vernier callipers & {$[74,103,104,107]$} & \\
\hline & Weighing & {$[70,108]$} & Infer volume fraction \\
\hline \multirow[t]{3}{*}{ Surface texture } & $\mathrm{XCT}$ & {$[31,56,71,77,79,87,109]$} & $\begin{array}{l}\text { Calculate } R a \text { value from strut profile } \\
\text { or cross-sectional area }\end{array}$ \\
\hline & Optical microscopy & {$[58,72,81,105]$} & $R a$ value from strut profile \\
\hline & SEM & {$[11,25,41,57,68,69,79,80,82-85,106]$} & Qualitative analysis \\
\hline \multirow[t]{4}{*}{ Porosity } & $\begin{array}{l}\text { Archimedes' } \\
\text { method }\end{array}$ & {$[24,57,75,92]$} & Infer porosity from weight in two fluids \\
\hline & $\mathrm{XCT}$ & {$[56,65,95,96]$} & Calculate total porosity \\
\hline & Optical microscopy & {$[87,90]$} & Average porosity determined from select cross-sections \\
\hline & SEM & [71] & Surface porosity \\
\hline
\end{tabular}

select number of cross-sections. SEM has also been used by Tancogne-Dejean et al. [71] to view surface porosity.

\subsection{Discussion of measurement methods}

Optical microscopy and SEM offer established, high resolution imaging methods, however, using these imaging methods to measure structures is challenging, as highlighted by Van Bael et al. [98] who found large differences between optical microscopy and XCT results for the diameter of designed pores, particularly for non-spherical designed pores. Additionally, in order to work within the smaller measurement volume, sample preparation will often require destroying the sample. Furthermore, to obtain porosity measurements, the sample is destroyed upon sectioning to view the pores and pore morphology may be modified. Pores can easily be undetected as only those exposed upon sectioning contribute towards the calculation.

One of the main strengths of XCT is its ability to image complex AM parts and assess dimensional inaccuracies; surface texture and porosity can all be assessed from the same measurement data. In this regard, XCT is superior to optical instruments which rely on line of sight and consistent reflective propertiesboth of which are hindered by AM surfaces through features such as high slopes and variable aspect-ratios [112]. A drawback of XCT measurements can be found in its long acquisition times and the current limited understanding of its range of influence factors (i.e. sources of variation within the measurement output [113]. Depending on the measurement task, influence factors can significantly alter results. For example, surface determination, which defines the material boundary, has been shown to cause greater errors in edge-to-edge length measurements over spherecentre distances [113]. These errors may cause strut diameter measurement to have less accuracy than when measuring the position of strut centres and node centres. Additionally, the alignment of XCT and CAD data is effective for analysing the overall geometry of a lattice. However, segmentation of individual features is a more informative approach for analysing local deviations. Furthermore, large-scale deviations, such as shrinkage and warping, present a challenge during alignment of significantly dissimilar geometries. For porosity measurement, employing a stitching method [95] enables detection of smaller pores through the smaller voxel size, however, errors may form at the boundaries of reconstructed volumes [113]. Lastly, an additional discussion on XCT is provided by Ho et al. [114], focusing on its suitability for the characterisation of lattices for biomedical applications.

The remaining approaches i.e. Vernier callipers, weighing and Archimedes' method all provide useful initial assessments of lattice quality but present repeatability challenges. For example, it may be unreliable to determine porosity with the Archimedes' method as its accuracy can be reduced due to surface pores and cracks which can cause infiltration of the soaking fluid [115].

Sample preparation can further effect measurement results, through procedures such as the removal of parts from the build bed. Sing et al. [74] found lattice height was reduced upon removal via electrical discharge machining. Data processing also has a strong influence over measurement results, for example, the selection of surface texture parameters. The parameter $R a$ is often used to describe surface texture, and has been useful for assessing lattice surfaces, however, it may inadequately capture complex 
information on AM surfaces [116]. There are investigations into employing areal parameters, which aim to more adequately capture AM surface information, such as $S a$, the areal counterpart of $R a$ [117]. Regarding instrumentation, XCT has been used to extract areal parameters from AM surfaces, however, only from planar surfaces, as in references [118-120].

\section{Methods for minimising defects}

This section details the methods used in the literature for improving the quality of lattice structures produced by PBF. The methods are categorised in chronological order, firstly design constraints, followed by process parameter optimisation and post-processing methods, thus considering all the stages at which the quality of the lattice can be influenced.

\subsection{Design constraints}

As previously discussed, the design of strut-based unit cells can be accuractely controlled through the dimensions of individual members. Therefore, there is more investigation in the literature into the design constraints on strut-based unit cells as opposed to surface-based, which are mathematically defined. Several studies in the literature have investigated lattice design constraints by considering strut diameter, strut overhang angle, designed pore size and volume fraction.

Regarding strut diameter, designed pore size and volume fraction, Melancon et al. [42] provide a thorough consideration of design constraints for Ti6Al4V tetrahedron and octet-truss unit cells produced by LM. The authors define an admissible design space by selecting a range of designed pore sizes and a maximum volume fraction required for bone ingrowth, that is $50 \mu \mathrm{m}$ to $650 \mu \mathrm{m}$ and $50 \%$, respectively. A minimum strut diameter of $0.2 \mathrm{~mm}$ is also defined, yielding a triangular design space as shown in Fig. 9. Arabnejad et al. [59] also use a similar design space for tetrahedron unit cells, however, with designed pore size ranging from $50 \mu \mathrm{m}$ to $800 \mu \mathrm{m}$. Melancon et al. assess the manufacturability of tetrahedron and octet-truss unit cells by producing several samples within this design space. For each unit cell, the strut diameter, designed pore diameter and volume fraction were each measured, calculating the relative error from nominal for strut diameter, volume fraction and designed pore size. The arithmetic mean of the relative errors was used to obtain an overall manufacturing error for each design. One of several results are shown in Fig. 9 which displays the overall manufacturing error for tetrahedral unit cells. The contour plot shows manufacturing error to increase to approximately $10 \%$ at the minimum strut diameter. Other observations included a maximum designed pore error of $18 \%$ at lowest strut diameter and a maximum error of $15 \%$ strut diameter upon decreasing volume fractions.

The minimum strut diameter constraint of $0.2 \mathrm{~mm}$ used by Melancon et al. is further supported by other studies. Further reduction in strut diameter is generally hindered by process limitations, particularly melt pool size. Van Bael et al. [97] found LM $0.1 \mathrm{~mm}$ diameter Ti6A14V struts unachievable due to a melt pool size of approximately $0.18 \mathrm{~mm}$, yielding a strut diameter of approximately twice the designed value. Strut oversizing due to the minimum melt pool size was also observed by Pyka et al. [79] and Sing et al. [104] who attempted strut diameters of $0.1 \mathrm{~mm}$ and $0.08 \mathrm{~mm}$, respectively.

Volume fraction has also been assessed by Al-Ketan et al. [70] ('relative density', in their paper), who highlight surface area as a useful indicator for determining deviation in volume fraction for several lattice structure designs. The error between designed and manufactured relative densities increased in unit cells with higher surface area, as a greater amount of powder can remain attached to the part. Deviations of $1 \%$ to $10 \%$ in volume fraction were found in the unit cells of lowest and highest surface area, respectively - the skeletal gyroid and sheet diamond (Fig. 10).
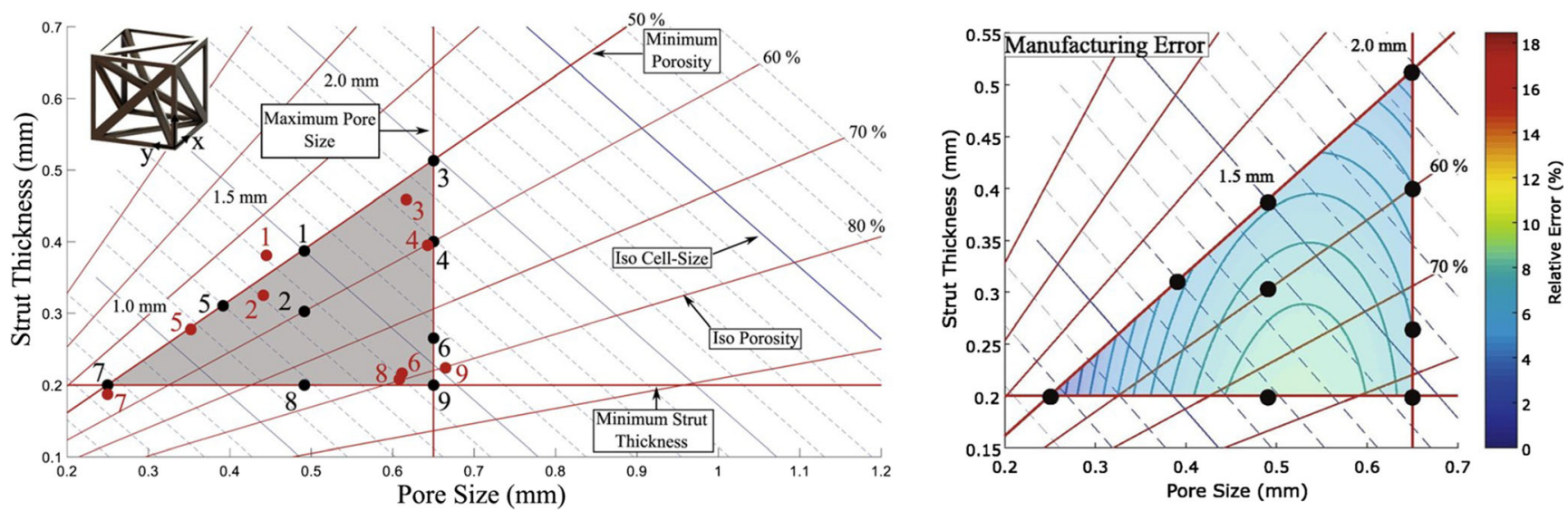

Fig. 9 Left, admissible design space for a tetrahedron-based unit cell. Here, 'pore size' refers to the designed pore size and 'porosity' to volume fraction. Right, the results contour map showing the overall manufacturing error for each sample [42] 
Fig. 10 Plot showing the deviation in volume fraction (here, termed 'relative density') for several unit cells. Inset table illustrates the relationship between surface area and deviation in volume fraction [70]

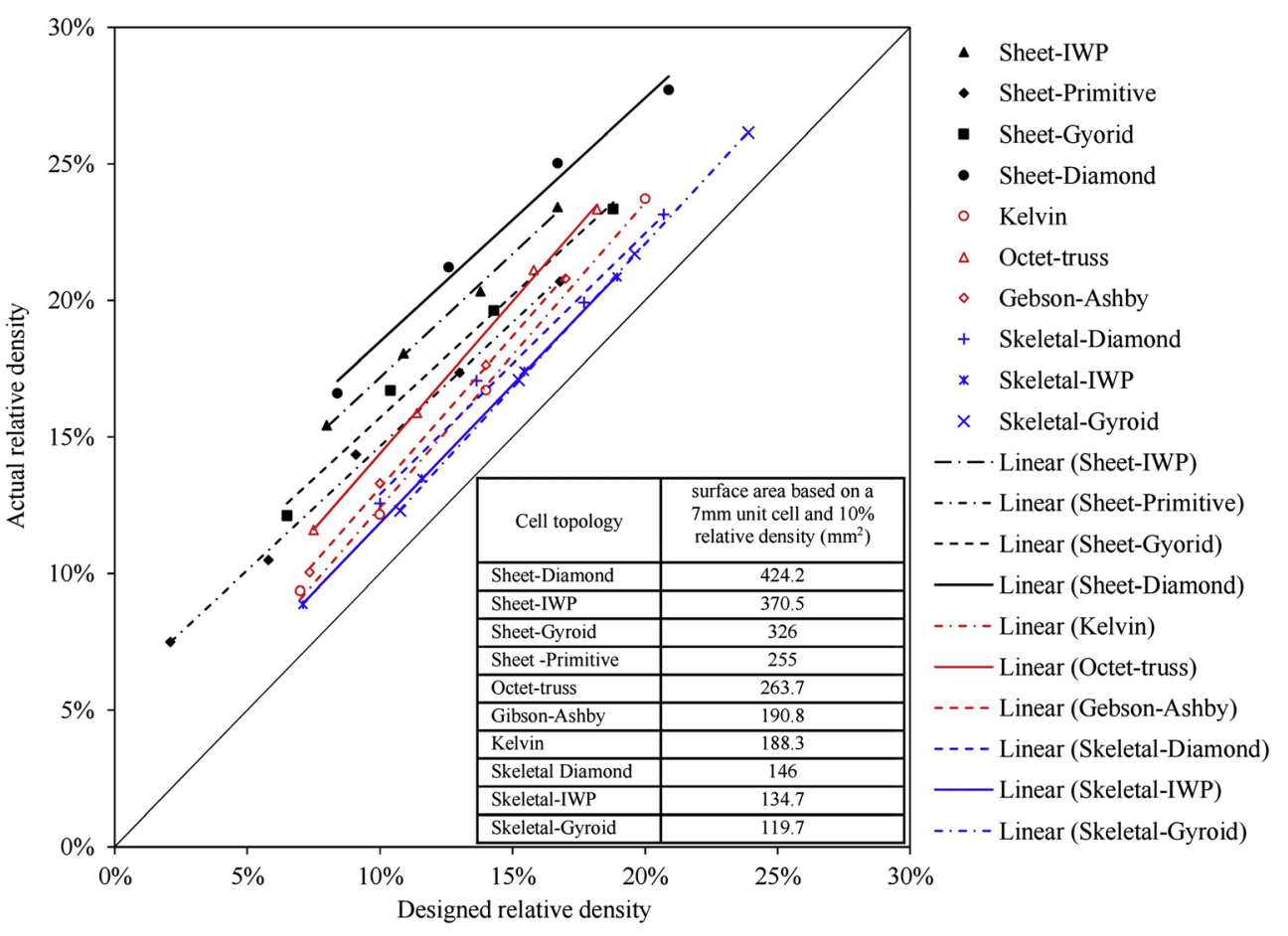

The overhang angle of struts (the angle between the struts and the build bed) is a key feature of lattice design, as support structures cannot be incorporated into designs. As mentioned in Sect. 4.2, horizontal struts have been successfully printed, albeit with significant deviations from their designed cylindrical shape. Yan et al. [24] comment on the importance of small overhang lengths for successfully achieving horizontal struts, as demonstrated with unit cells approximately $3 \times 3 \times 3 \mathrm{~mm}$ in size. Yan et al. [25] used the skeletal gyroid unit cell to demonstrate that manufacturing horizontal struts is more achievable when non-prismatic struts are used. The struts in the skeletal gyroid unit cell exhibit a continuous change in inclination angle, allowing for horizontal struts to be successfully printed. These observations from Yan et al. may also explain the previously discussed observations by AlKetan [70] in Sect. 4.2, regarding a less pronounced stair stepping effect in surface-based unit cells in comparison with strut based. Similarly, Li et al. [69] manufactured horizontal struts by linearly increasing strut diameter.

Regarding prismatic struts, Calignano defined the minimum angle for overhanging struts to be $30^{\circ}$ from the build bed, for LM of AlSi10Mg and Ti6Al4V [76], which prevents aggravation of the stair stepping effect. Mazur et al. [121, 122] found a minimum strut angle and diameter of $20^{\circ}$ and $0.3 \mathrm{~mm}$ respectively for LM of Ti6Al4V and H13 tool steel struts. Wang et al. [81] provides a comprehensive study on the manufacturability of the octahedral unit cell using $316 \mathrm{~L}$ stainless steel. A 'critical fabrication zone' of $35^{\circ}$ to $40^{\circ}$ was found for the strut overhang angle. Angles above this range were regarded as safe to print and those below were prone to failure. For EBM of Ti6Al4V, Cansizoglu et al. [123] states a minimum strut diameter of $0.7 \mathrm{~mm}$ and overhang angle of $20^{\circ}$.

There have been several studies optimising lattice designs by considering the inherent defects which form. Simple approaches to design optimisation have proven effective, for example Bagheri et al. [124] altered strut diameters to compensate for orientation-dependent overor under-sizing (Fig. 11). The results included a reduction in strut diameter deviation from $60 \%$ to $3 \%$ and additional compression tests on compensated lattices showed better agreement with simulations. Li et al. [107] increased the diameter of designed pores to accommodate for later shrinkage due to excess consolidation of material. Similarly, irregular, material accumulation was combated by Li et al. [69], by increasing strut diameters near the nodes.

\subsection{Processing parameters}

Recalling Eq. (2) from Sect. 3, the process parameters governing energy density are often investigated to optimise part quality. Laser power has been investigated in several studies. Sing et al. [104] compared the effects of laser power, layer thickness and scanning speed on strut diameter and concluded that struts were most sensitive to laser power. An increase of laser power from $120 \mathrm{~W}$ to $240 \mathrm{~W}$ caused strut diameters to increase more than twofold. Qiu et al. [87] found strut diameters to increase by over $60 \%$ upon increasing laser power from $150 \mathrm{~W}$ to $400 \mathrm{~W}$, with the amount of attached particles 
Fig. 11 XCT image of uncompensated unit cell (left) and the compensated unit cell (right). Red-dashed lines show the initial unit cell design [124]
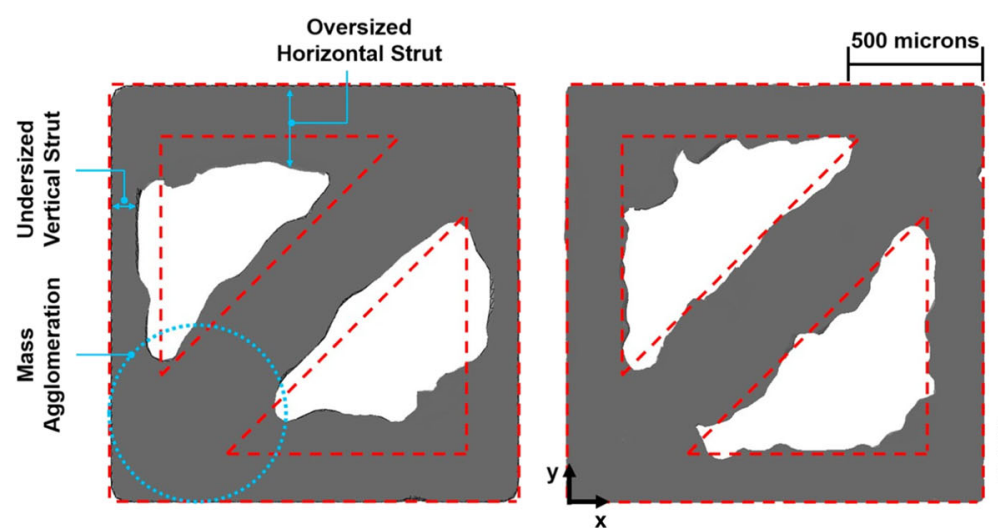

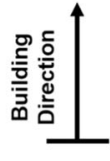

also increasing (Fig. 12). Shen et al. [11] also observed, over a smaller range $(80 \mathrm{~W}$ to $120 \mathrm{~W})$ increasing diameter at higher laser powers. Using SEM, Hrabe et al. [83] observed smoother surfaces at higher energy input. Additional tests by Qiu et al. [87], across the same power range ( $150 \mathrm{~W}$ to $400 \mathrm{~W})$, saw a peak porosity content of $2 \%$ at a laser power of $200 \mathrm{~W}$.

Scan speeds have also been investigated. The length-to-width ratio of the melt pool is greatly controlled by scanning speed, where at higher speeds the ratio increases and in severe cases the melt pool can become unstable and separate [54]. Qiu et al. [87] observed that increasing the scanning speed from $3000 \mathrm{~mm} / \mathrm{s}$ to $7000 \mathrm{~mm} / \mathrm{s}$ caused an initial decrease in strut diameter, followed by no effect at speeds above $4000 \mathrm{~mm} / \mathrm{s}$. Sing et al. [74] also found increasing scanning speed to cause a reduction in strut diameter. Han et al. highlighted effects of scan strategy on strut size, citing reference [101], explaining that continuous scan paths thatmake au-turn at the ends of profiles will cause strut oversizing [36].

\subsection{Post-processing}

Post-processing techniques have proven effective for reducing the remaining defects. This section discusses post-processing methods for improving surface texture and porosity.

To reduce the surface texture of AM parts, mechanical surface treatment methods, such as sandblasting, are commonly used [57,73], however, limited access to the internal features in lattice structures may prove difficult to treat, as highlighted by Hollander et al. [73]. Xuanyong et al. [125] provide a thorough review of procedures for surface modification of titanium and its alloys, focusing on chemical and physical methods, such as chemical etching and thermal spraying, respectively.

Chemical etching has been used in several studies to investigate its effect on Ti6Al4V lattice structures [77, 79, 109, 126]. Taking an illustrative example, de Formanoir [109] investigated the effect of hydrofluoric acid and nitric acid solutions on the a

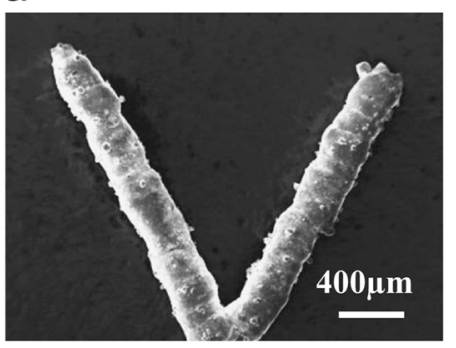

b

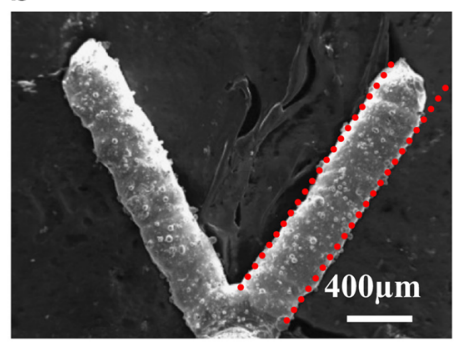

d

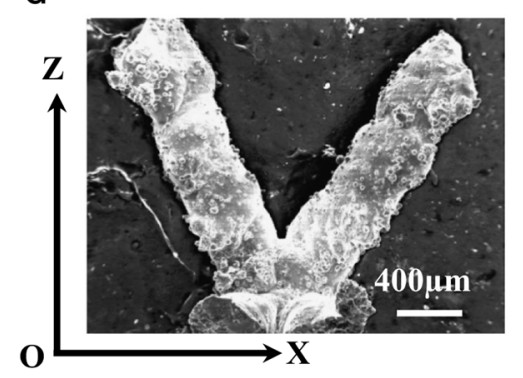

e

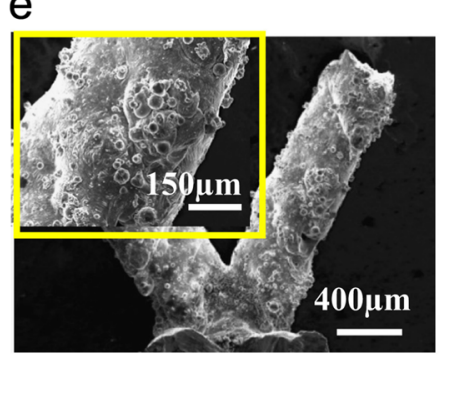

C

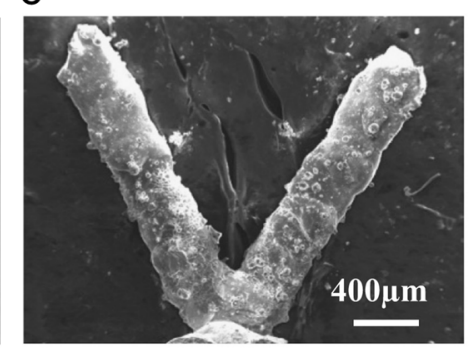

$f$

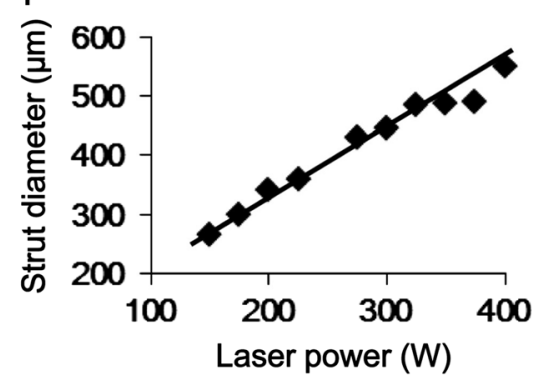

Fig. 12 An example of the effects of laser power on strut diameter, provided by [87] 
surface texture of Ti6Al4V octet lattice structures. A clear decrease in attached particles was observed, as shown in Fig. 13, with supporting $R a$ and $R t$ values, determined from XCT data. The etching process also caused the volume fraction to decrease by approximately $7 \%$. Compression tests revealed a reduction in stiffness upon etching, with this reduction being proportional to the change in volume fraction. Chemical etching was also observed to reduce the discrepancies between experimentally determined and simulated stiffness values. This better agreement with simulation data was attributed to the removal of attached particles which allowed for a better representation of ideal, cylindrical struts.

To reduce the porosity in AM parts, hot isostatic pressing is commonly used, where porous parts are subjected to high pressure and temperature [127-129]. Wu et al. [130] observed a significant improvement in fatigue properties upon hot isostatic pressing of Ti6Al4V lattice structures, quantified by an increased endurance ratio of approximately $80 \%$. The improved fatigue properties were attributed to a phase change from brittle $\alpha^{\prime}$-martensite to tough $\alpha+\beta$ mixed phases causing an increase in toughness - the key material property for resisting crack propagation. A 20\% and 30\% reduction in hardness and yield strength respectively was also recorded. Hot isostatic pressing was also performed by Dutton et al. [131] on EBM and LM parts. It was observed that for LM parts, the high pressure caused the gas filled pores to compress into sharp edges. However, EBM parts were unaffected due to the evacuated chamber preventing gas filled pores from forming.

Van Hooreweder et al. [132] compared the effects of stress relieving, hot isostatic pressing and chemical etching on the fatigue properties of Ti6Al4V lattice structures. The results showed chemical etching as significantly superior, due to the removal of attached powder yielding smoother surfaces.

\section{Summary and conclusions}

This review aims to serve as a resource on manufacturing defects in lattice structures produced by PBF. A review of defects in lattice structures manufactured by powder bed fusion processes has been presented, discussing how dimensional inaccuracies, surface defects and porosity have been observed in different designs. Additional topics of general defect formation mechanisms in PBF processes, quality inspection and defect minimisation methods have been included as supporting sections. To summarise, the questions from Sect. 1.1 are readdressed.

1. How do defects form in powder bed fusion processes?

There are numerous studies investigating defect formation mechanisms in PBF processes. It is often documented that melt pool instabilities and the heating/cooling mechanisms give rise to pores, dimensional inaccuracies and surface defects, where pores are often formed through entrapped gases and unmelted powders, dimensional inaccuracies through residual stresses and surface defects through melt pool instabilities.

\section{What type of defects form in lattice structures?}

Defects in strut-based lattices were found to be considerably more documented in the literature in comparison with those found in surface-based lattices. Dimensional inaccuracies are often documented for strut-based designs, with defects such as varying diameter, strut waviness, material accumulation and severe orientation dependency in the struts.

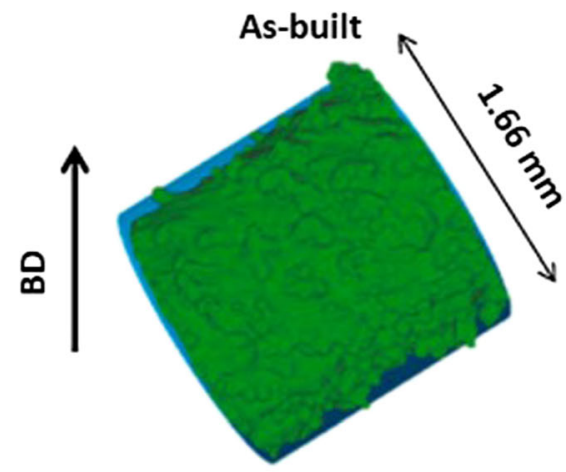

Relative density: $\mathbf{2 8 . 5 \%}$

$$
\begin{aligned}
& \mathrm{R}_{\mathrm{a}}: 34.3 \mu \mathrm{m} \\
& \mathrm{R}_{\mathrm{t}}: \mathbf{1 8 1 . 7} \mu \mathrm{m}
\end{aligned}
$$

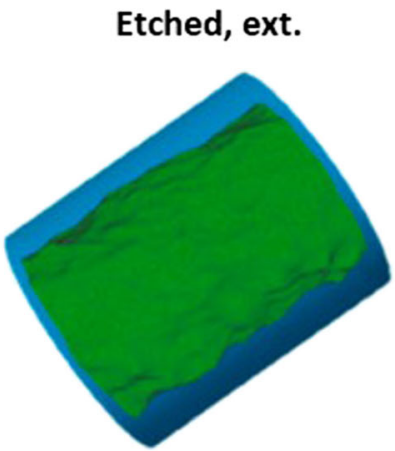

Relative density: $\mathbf{2 1 \%}$

$R_{\mathrm{a}}: 23.8 \mu \mathrm{m}$

$R_{\mathrm{t}}: 110 \mu \mathrm{m}$

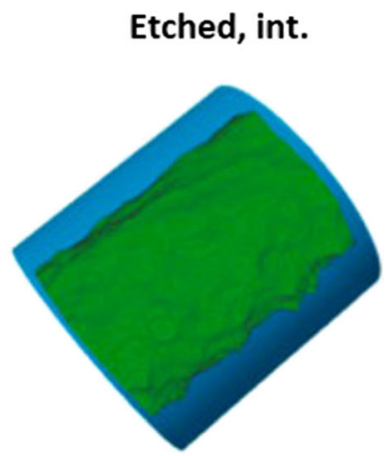

Relative density: $21 \%$

$$
R_{\mathrm{a}}: 25.9 \mu \mathrm{m}
$$$$
R_{\mathrm{t}}: \mathbf{1 2 1 . 5} \mu \mathrm{m}
$$

Fig. 13 Example of the effects of chemical etching. XCT reconstruction of Ti6Al4V struts before and after chemical etching, with accompanying volume fraction (here, termed 'relative density'), $R a$ and $R t$ values. BD, build direction; etched, ext./int, chemically etched struts in exterior/ interior locations within the lattice [109] 
Surface defects have been observed to be highly dependent on orientation, as is the case in general for PBF parts, with down-skin surfaces yielding rougher surfaces, supported by extracted surface texture parameters. The stair stepping effect was seen to be less severe in surface-based designs, due to the continuously varying inclination angles on the surfaces.

Porosity has been particularly documented in several strutbased designs, where larger pores have been observed in nodal areas. Strut orientation has also been documented to influence porosity, where lower inclination angles yield higher porosity, with the pore distribution grouping towards the lower region of the struts.

3. How can defects be appropriately measured in lattice structures?

From the literature in this review, XCT is often used to inspect the quality of lattice structures, which enables dimensional inaccuracies, surface texture and porosity to be assessed from the same data set. Limitations include long acquisition times and a limited understanding of the effect on measurement uncertainty of various influence factors. It has been shown that XCT voxel size limits the detectable porositystitching methods can improve this but introduce new errors when combining multiple scanning data sets. Additional established methods such as optical microscopy and SEM remain effective for inspecting defects within significantly smaller measurement volumes. Inexpensive techniques and apparatus such as Archimedes' method, and Vernier callipers remain as useful tools for porosity and dimensional measurements, respectively.

\section{How can defect formation be minimised?}

There are several methods employed to minimise defect formation in lattice structures; this has been attempted through development of design maps, design constraints, process parameters and post-processing. Dimensional inaccuracies can also be significantly reduced by accounting for orientation dependent errors measured from test samples.

Energy density calculations continue as an appropriate method for assessing primary process parameters. Expected results have been observed: increased laser/electron beam power increases strut size, increase scanning strategy reduces strut size. Scanning profiles can further influence strut size, particularly at the ends of scanning paths.

Post-processing methods have been documented as particularly useful for reducing surface irregularities, however, limited access to the lattice geometry inhibits the performance of mechanical processes such as sandblasting. Chemical etching, which circumvents problems due to limited access, provides no control over specific regions of interest and alters mechanical properties of the lattice, for example causing a reduction in stiffness. Chemical etching has been observed as significantly superior for improving fatigue properties than stress relieving and hot isostatic pressing.

Looking forward, further research opportunities include more in-depth characterisation of manufacturing defects in surface-based lattice structures, as the literature found for the review was heavily skewed towards strut based. Continued development of design maps for individual unit cells will help increase understanding of their manufacturability. Additionally, incorporating defects into existing lattice structure models will be useful for quantifying the influence of defects on the desired function of the lattice [133]. From a metrology perspective, process monitoring methods will aid in increasing understanding of defect formation, particularly regarding the influence of process parameters. Furthermore, the popularity of XCT must be met with establishing traceability, providing confidence to the measurement of defects. Overall, this content, and subsequent work in the field, will contribute towards a better understanding of defects in PBF lattice structures, accelerating the application of functional lattice structures into various industries.

Acknowledgements The authors gratefully acknowledge the help and support of Dr Ian Maskery, Dr Adam Thompson and Mr Waiel Elmadih of the University of Nottingham.

Funding information This work was supported by the Engineering and Physical Sciences Research Council (grant numbers EP/M008983/1, EP/ L01534X/1).

Open Access This article is licensed under a Creative Commons Attribution 4.0 International License, which permits use, sharing, adaptation, distribution and reproduction in any medium or format, as long as you give appropriate credit to the original author(s) and the source, provide a link to the Creative Commons licence, and indicate if changes were made. The images or other third party material in this article are included in the article's Creative Commons licence, unless indicated otherwise in a credit line to the material. If material is not included in the article's Creative Commons licence and your intended use is not permitted by statutory regulation or exceeds the permitted use, you will need to obtain permission directly from the copyright holder. To view a copy of this licence, visit http://creativecommons.org/licenses/by/4.0/.

\section{References}

1. Gibson LJ, Ashby MF (1997) Cellular solids: structure and properties. Cambridge University Press, Cambridge

2. Banhart J (2001) Manufacture, characterisation and application of cellular metals and metal foams. Prog Mater Sci 46:559-632. https://doi.org/10.1016/S0079-6425(00)00002-5

3. Maskery I, Sturm L, Aremu AO, Panesar A, Williams CB, Tuck CJ, Wildman RD, Ashcroft IA, Hague RJM (2018) Insights into the mechanical properties of several TPMS lattice structures made by polymer additive manufacturing. Polymer (Guildf) 152:62-71. https://doi.org/10.1016/j.polymer.2017.11.049

4. Tamburrino F, Graziosi S, Bordegoni M (2018) The design process of additively manufactured mesoscale lattice structures: a 
review. J Comput Inf Sci Eng 18:040801. https://doi.org/10.1115/ 1.4040131

5. Schaedler TA, Jacobsen AJ, Torrents A, Sorensen AE, Lian J, Greer JR, Valdevit L, Carter WB (2011) Ultralight metallic microlattices. Science 334:962-965. https://doi.org/10.1126/ science. 1211649

6. Haack DP, Butcher KR, Kim T, Lu TJ, Hoduston HP, Lu TJ (2001) Novel lightweight metal foam heat exchangers. 1-7

7. Calmidi VV, Mahajan RL (2000) Forced convection in high porosity metal foams. J Heat Transf 122:557-565. https://doi.org/10. $1115 / 1.1287793$

8. Boomsma K, Poulikakos D, Zwick F (2003) Metal foams as compact high performance heat exchangers. Mech Mater 35:11611176. https://doi.org/10.1016/j.mechmat.2003.02.001

9. Roper CS, Fink KD, Lee ST, Kolodziejska JA, Jacobsen AJ (2013) Anisotropic convective heat transfer in microlattice materials. AICHE J 59:622-629. https://doi.org/10.1002/aic.13821

10. Hasan R, Mines RAW, Shen E, Tsopanos S, Cantwell WJ, Brooks W, Sutcliffe CJ (2010) Comparison of the drop weight impact performance of sandwich panels with aluminium honeycomb and titanium alloy micro lattice cores. Appl Mech Mater 24-25: 413-418. https://doi.org/10.4028/www.scientific.net/AMM.2425.413

11. Shen Y, Cantwell W, Mines R, Li Y (2014) Low-velocity impact performance of lattice structure core based sandwich panels. J Compos Mater 48:3153-3167. https://doi.org/10.1177/ 0021998313507616

12. Wang X, Xu S, Zhou S, Xu W, Leary M, Choong P, Qian M, Brandt M, Xie YM (2016) Topological design and additive manufacturing of porous metals for bone scaffolds and orthopaedic implants: a review. Biomaterials 83:127-141. https://oi.org/ 10.1016/j.biomaterials.2016.01.012

13. Li X, Wang C-T, Zhang W-G, Li Y-C (2009) Properties of a porous Ti-6 $\mathrm{Al}-4 \mathrm{~V}$ implant with a low stiffness for biomedical application. Proc Inst Mech Eng Part H J Eng Med 223:173178. https://doi.org/10.1243/09544119JEIM466

14. Rodgers GW, Van Houten EEW, Bianco RJ, Besset R, Woodfield TBF (2014) Topology optimization of porous lattice structures for orthopaedic implants. IFAC Proc Vol 47:9907-9912. https://doi. org/10.3182/20140824-6-ZA-1003.00924

15. Williams JM, Adewunmi A, Schek RM, Flanagan CL, Krebsbach PH, Feinberg SE, Hollister SJ, Das S (2005) Bone tissue engineering using polycaprolactone scaffolds fabricated via selective laser sintering. Biomaterials 26:4817-4827. https://doi.org/10.1016/j. biomaterials.2004.11.057

16. Lietaert K, Cutolo A, Boey D, Van Hooreweder B (2018) Fatigue life of additively manufactured Ti6Al4V scaffolds under tension-tension, tension-compression and compression-compression fatigue load. Sci Rep 8:1-9. https://doi.org/10.1038/s41598-018-23414-2

17. Zhang XZ, Leary M, Tang HP, Song T, Qian M (2018) Selective electron beam manufactured Ti-6Al-4V lattice structures for orthopedic implant applications: current status and outstanding challenges. Curr Opin Solid State Mater Sci 22:75-99. https://doi.org/ 10.1016/j.cossms.2018.05.002

18. Grasso M, Colosimo BM (2017) Process defects and in situ monitoring methods in metal powder bed fusion: a review. Meas Sci Technol:28. https://doi.org/10.1088/1361-6501/aa5c4f

19. Şen A, Quilhó T, Pereira H (2011) The cellular structure of cork from Quercus cerris var. cerris bark in a materials' perspective. Ind Crop Prod 34:929-936. https://doi.org/10.1016/j.indcrop.2011.02.015

20. Pavlou DG (2015) Essentials of the finite element method: for mechanical and structural engineers. Elsevier Science

21. Maskery I, Aboulkhair NT, Aremu AO, Tuck CJ, Ashcroft IA, Wildman RD, Hague RJM (2016) A mechanical property evaluation of graded density Al-Si10-mg lattice structures manufactured by selective laser melting. Mater Sci Eng A 670:264-274. https:// doi.org/10.1016/j.msea.2016.06.013

22. Murr LE, Gaytan SM, Medina F, Martinez E, Martinez JL, Hernandez DH, Machado BI, Ramirez DA, Wicker RB (2010) Characterization of Ti-6Al-4V open cellular foams fabricated by additive manufacturing using electron beam melting. Mater Sci Eng A 527:1861-1868. https://doi.org/10.1016/j.msea.2009.11.015

23. Helou M, Kara S (2018) Design, analysis and manufacturing of lattice structures: an overview. Int J Comput Integr Manuf 31:243261. https://doi.org/10.1080/0951192X.2017.1407456

24. Yan C, Hao L, Hussein A, Raymont D (2012) Evaluations of cellular lattice structures manufactured using selective laser melting. Int J Mach Tools Manuf 62:32-38. https://doi.org/10.1016/j. ijmachtools.2012.06.002

25. Yan C, Hao L, Hussein A, Young P, Raymont D (2014) Advanced lightweight $316 \mathrm{~L}$ stainless steel cellular lattice structures fabricated via selective laser melting. Mater Des 55:533-541. https://doi. org/10.1016/j.matdes.2013.10.027

26. Ahmadi SM, Campoli G, Amin Yavari S, Sajadi B, Wauthle R, Schrooten J, Weinans H, Zadpoor AA (2014) Mechanical behavior of regular open-cell porous biomaterials made of diamond lattice unit cells. J Mech Behav Biomed Mater 34:106-115. https://doi.org/10.1016/j.jmbbm.2014.02.003

27. Zhang B, Li Y, Bai Q (2017) Defect formation mechanisms in selective laser melting: a review. Chinese J Mech Eng 30:515527. https://doi.org/10.1007/s10033-017-0121-5

28. $\mathrm{Li} \mathrm{T}, \mathrm{Wu} \mathrm{Y,} \mathrm{He} \mathrm{J} \mathrm{(2018)} \mathrm{Main} \mathrm{defects} \mathrm{observed} \mathrm{in} \mathrm{aluminum} \mathrm{alloy}$ parts produced by SLM: from causes to consequences. Addit Manuf. https://doi.org/10.1016/j.procbio.2018.02.003

29. Ashby MF (2006) The properties of foams and lattices. Philos Trans R Soc A Math Phys Eng Sci 364:15-30. https://doi.org/ 10.1098/rsta.2005.1678

30. Schoen AH (1970) Infinite periodic minimal surfaces without selfintersections. NASA, Cambridge

31. Lin C-Y, Wirtz T, LaMarca F, Hollister SJ (2007) Structural and mechanical evaluations of a topology optimized titanium interbody fusion cage fabricated by selective laser melting process. J Biomed Mater Res Part A 83A:272-279. https://doi.org/ 10.1002/jbm.a.31231

32. Elmadih W, Syam WP, Maskery I, Leach RK (2018) Designing low frequency bandgaps in additively manufactured parts using internal resonators. Proc ASPE

33. Panesar A, Abdi M, Hickman D, Ashcroft I (2018) Strategies for functionally graded lattice structures derived using topology optimisation for additive manufacturing. Addit Manuf 19:81-94. https://doi.org/10.1016/J.ADDMA.2017.11.008

34. Ahmadi SM, Yavari SA, Wauthle R, Pouran B, Schrooten J, Weinans H, Zadpoor AA (2015) Additively manufactured opencell porous biomaterials made from six different space-filling unit cells: the mechanical and morphological properties. Materials (Basel) 8:1871-1896. https://doi.org/10.3390/ma8041871

35. Gorny B, Niendorf T, Lackmann J, Thoene M, Troester T, Maier HJ (2011) In situ characterization of the deformation and failure behavior of non-stochastic porous structures processed by selective laser melting. Mater Sci Eng A 528:7962-7967. https://doi. org/10.1016/j.msea.2011.07.026

36. Han C, Li Y, Wang Q, Wen S, Wei Q, Yan C, Hao L, Liu J, Shi Y (2018) Continuous functionally graded porous titanium scaffolds manufactured by selective laser melting for bone implants. J Mech Behav Biomed Mater 80:119-127. https://doi.org/10.1016/j. jmbbm.2018.01.013

37. Dallago M, Fontanari V, Torresani E, Leoni M, Pederzolli C, Potrich C, Benedetti M (2018) Fatigue and biological properties of Ti-6Al-4V ELI cellular structures with variously arranged cubic cells made by selective laser melting. J Mech Behav Biomed Mater 78:381-394. https://doi.org/10.1016/j.jmbbm.2017.11.044 
38. Du Plessis A, Kouprianoff D, Yadroitsava I, Yadroitsev I (2018) Mechanical properties and in situ deformation imaging of microlattices manufactured by laser based powder bed fusion. https://doi.org/10.3390/ma11091663

39. Gümrük R, Mines RAW (2013) Compressive behaviour of stainless steel micro-lattice structures. Int J Mech Sci 68:125-139. https://doi.org/10.1016/j.ijmecsci.2013.01.006

40. Latture RM, Rodriguez RX, Holmes LR, Zok FW (2018) Effects of nodal fillets and external boundaries on compressive response of an octet truss. Acta Mater 149:78-87. https://doi.org/10.1016/j. actamat.2017.12.060

41. Cheng XY, Li SJ, Murr LE, Zhang ZB, Hao YL, Yang R, Medina F, Wicker RB (2012) Compression deformation behavior of Ti$6 \mathrm{Al}-4 \mathrm{~V}$ alloy with cellular structures fabricated by electron beam melting. J Mech Behav Biomed Mater 16:153-162. https://doi. org/10.1016/j.jmbbm.2012.10.005

42. Melancon D, Bagheri ZS, Johnston RB, Liu L, Tanzer M, Pasini D (2017) Mechanical characterization of structurally porous biomaterials built via additive manufacturing: experiments, predictive models, and design maps for load-bearing bone replacement implants. Acta Biomater 63:350-368. https://doi.org/10.1016/j.actbio.2017.09.013

43. Sercombe TB, Xu X, Challis VJ, Green R, Yue S, Zhang Z, Lee PD (2015) Failure modes in high strength and stiffness to weight scaffolds produced by selective laser melting. Mater Des 67:501508. https://doi.org/10.1016/j.matdes.2014.10.063

44. ISO (2017) Additive manufacturing-general principlesterminology

45. Gibson I, Rosen DW, Stucker B (2010) Additive manufacturing technologies. Springer

46. Carter LN, Wang X, Read N, Khan R, Aristizabal M, Essa K, Attallah MM (2015) Process optimisation of selective laser melting using energy density model for nickel based superalloys. Mater Sci Technol 0836:1-5. https://doi.org/10.1179/1743284715y. 0000000108

47. Gong H, Rafi K, Gu H, Starr T, Stucker B (2014) Analysis of defect generation in Ti-6Al-4V parts made using powder bed fusion additive manufacturing processes. Addit Manuf 1:87-98. https://doi.org/10.1016/j.addma.2014.08.002

48. Tammas-Williams S, Zhao H, Léonard F, Derguti F, Todd I, Prangnell PB (2015) XCT analysis of the influence of melt strategies on defect population in Ti-6Al-4V components manufactured by selective electron beam melting. Mater Charact 102:47-61. https://doi.org/10.1016/j.matchar.2015.02.008

49. Sun S, Brandt M, Easton M (2016) Powder bed fusion processes: an overview. Elsevier Ltd

50. Mercelis P, Kruth JP (2006) Residual stresses in selective laser sintering and selective laser melting. Rapid Prototyp J 12:254 265. https://doi.org/10.1108/13552540610707013

51. Thijs L, Verhaeghe F, Craeghs T, Van Humbeeck J, Kruth JP (2010) A study of the microstructural evolution during selective laser melting of Ti-6Al-4V. Acta Mater 58:3303-3312. https://doi. org/10.1016/j.actamat.2010.02.004

52. Seifi M, Salem A, Beuth J, Harrysson O, Lewandowski JJ (2016) Overview of materials qualification needs for metal additive manufacturing. Jom 68:747-764. https://doi.org/10.1007/ s11837-015-1810-0

53. Sames WJ, List FA, Pannala S, Dehoff RR, Babu SS (2016) The metallurgy and processing science of metal additive manufacturing. Int Mater Rev 61:315-360. https://doi.org/10.1080/ 09506608.2015.1116649

54. Li R, Liu J, Shi Y, Wang L, Jiang W (2012) Balling behavior of stainless steel and nickel powder during selective laser melting process. Int J Adv Manuf Technol 59:1025-1035. https://doi. org/10.1007/s00170-011-3566-1

55. Wang D, Wu S, Fu F, Mai S, Yang Y, Liu Y, Song C (2017) Mechanisms and characteristics of spatter generation in SLM processing and its effect on the properties. Mater Des 117:121130. https://doi.org/10.1016/j.matdes.2016.12.060

56. du Plessis A, Yadroitsava I, Yadroitsev I (2018) Ti6Al4V lightweight lattice structures manufactured by laser powder bed fusion for load-bearing applications. Opt Laser Technol 108:521-528. https://doi.org/10.1016/j.optlastec.2018.07.050

57. Yan C, Hao L, Hussein A, Young P (2015) Ti-6Al-4V triply periodic minimal surface structures for bone implants fabricated via selective laser melting. J Mech Behav Biomed Mater 51:6173. https://doi.org/10.1016/j.jmbbm.2015.06.024

58. Parthasarathy J, Starly B, Raman S, Christensen A (2010) Mechanical evaluation of porous titanium (Ti6Al4V) structures with electron beam melting (EBM). J Mech Behav Biomed Mater 3:249-259. https://doi.org/10.1016/j.jmbbm.2009.10.006

59. Arabnejad S, Burnett Johnston R, Pura JA, Singh B, Tanzer M, Pasini D (2016) High-strength porous biomaterials for bone replacement: a strategy to assess the interplay between cell morphology, mechanical properties, bone ingrowth and manufacturing constraints. Acta Biomater 30:345-356. https://doi.org/10.1016/j. actbio.2015.10.048

60. Zhang L, Feih S, Daynes S, Chang S, Wang MY, Wei J, Lu WF (2018) Energy absorption characteristics of metallic triply periodic minimal surface sheet structures under compressive loading. Addit Manuf 23:505-515. https://doi.org/10.1016/j.addma.2018. 08.007

61. Ataee A, Li Y, Fraser D, Song G, Wen C (2018) Anisotropic Ti6Al-4V gyroid scaffolds manufactured by electron beam melting (EBM) for bone implant applications. Mater Des 137:345-354. https://doi.org/10.1016/j.matdes.2017.10.040

62. Lozanovski B, Leary M, Tran P, Shidid D, Qian M, Choong P, Brandt M (2019) Computational modelling of strut defects in SLM manufactured lattice structures. Mater Des 171:107671. https://doi.org/10.1016/j.matdes.2019.107671

63. Cuadrado A, Yánez A, Martel O, Deviaene S, Monopoli D (2017) Influence of load orientation and of types of loads on the mechanical properties of porous Ti6A14V biomaterials. Mater Des 135: 309-318. https://doi.org/10.1016/j.matdes.2017.09.045

64. Liu L, Kamm P, García-Moreno F, Banhart J, Pasini D (2017) Elastic and failure response of imperfect three-dimensional metallic lattices: the role of geometric defects induced by selective laser melting. J Mech Phys Solids 107:160-184. https://doi.org/10. 1016/j.jmps.2017.07.003

65. Dong Z, Liu Y, Li W, Liang J (2019) Orientation dependency for microstructure, geometric accuracy and mechanical properties of selective laser melting AlSi10Mg lattices. J Alloys Compd 791: 490-500. https://doi.org/10.1016/j.jallcom.2019.03.344

66. Dallago M, Winiarski B, Zanini F, Carmignato S, Benedetti M (2019) On the effect of geometrical imperfections and defects on the fatigue strength of cellular lattice structures additively manufactured via selective laser melting. Int J Fatigue 124:348 360. https://doi.org/10.1016/j.ijfatigue.2019.03.019

67. Choy SY, Sun CN, Leong KF, Wei J (2017) Compressive properties of Ti-6Al-4V lattice structures fabricated by selective laser melting: design, orientation and density. Addit Manuf 16:213224. https://doi.org/10.1016/j.addma.2017.06.012

68. Gümrük R, Mines RAW, Karadeniz S (2013) Static mechanical behaviours of stainless steel micro-lattice structures under different loading conditions. Mater Sci Eng A 586:392-406. https://doi. org/10.1016/j.msea.2013.07.070

69. Li S, Hassanin H, Attallah MM, Adkins NJE, Essa K (2016) The development of TiNi-based negative Poisson's ratio structure using selective laser melting. Acta Mater 105:75-83. https://doi. org/10.1016/j.actamat.2015.12.017

70. Al-Ketan O, Rowshan R, Abu Al-Rub RK (2018) Topologymechanical property relationship of $3 \mathrm{D}$ printed strut, skeletal, 
and sheet based periodic metallic cellular materials. Addit Manuf 19:167-183. https://doi.org/10.1016/j.addma.2017.12.006

71. Tancogne-Dejean T, Spierings AB, Mohr D (2016) Additivelymanufactured metallic micro-lattice materials for high specific energy absorption under static and dynamic loading. Acta Mater 116:14-28. https://doi.org/10.1016/j.actamat.2016.05.054

72. Leary M, Mazur M, Elambasseril J, McMillan M, Chirent T, Sun Y, Qian M, Easton M, Brandt M (2016) Selective laser melting (SLM) of AlSi12Mg lattice structures. Mater Des 98:344-357. https://doi.org/10.1016/j.matdes.2016.02.127

73. Hollander DA, Von Walter M, Wirtz T, Sellei R, SchmidtRohlfing B, Paar O, Erli HJ (2006) Structural, mechanical and in vitro characterization of individually structured Ti-6Al-4V produced by direct laser forming. Biomaterials 27:955-963. https:// doi.org/10.1016/j.biomaterials.2005.07.041

74. Sing SL, Yeong WY, Wiria FE, Tay BY (2016) Characterization of titanium lattice structures fabricated by selective laser melting using an adapted compressive test method. Exp Mech 56:735748. https://doi.org/10.1007/s11340-015-0117-y

75. Choy SY, Sun CN, Leong KF, Wei J (2017) Compressive properties of functionally graded lattice structures manufactured by selective laser melting. Mater Des 131:112-120. https://doi.org/10. 1016/j.matdes.2017.06.006

76. Calignano F (2014) Design optimization of supports for overhanging structures in aluminum and titanium alloys by selective laser melting. Mater Des 64:203-213. https://doi.org/10.1016/j.matdes. 2014.07.043

77. Kerckhofs G, Pyka G, Moesen M, Schrooten J (2012) Highresolution micro-CT as a tool for 3D surface roughness measurement of 3D additive manufactured porous structures. Proc iCT 77-83. doi: https://doi.org/10.1002/adem.201200156

78. ISO (2005) Geometrical product specifications (GPS) - surface texture: profile method - terms, definitions and surface texture parameters (Corr 2)

79. Pyka G, Kerckhofs G, Papantoniou I, Speirs M, Schrooten J, Wevers M (2013) Surface roughness and morphology customization of additive manufactured open porous Ti6A14V structures. Materials (Basel) 6:4737-4757. https://doi.org/10.3390/ ma6104737

80. Sallica-Leva E, Jardini AL, Fogagnolo JB (2013) Microstructure and mechanical behavior of porous Ti-6Al-4V parts obtained by selective laser melting. J Mech Behav Biomed Mater 26:98-108. https://doi.org/10.1016/j.jmbbm.2013.05.011

81. Wang D, Yang Y, Liu R, Xiao D, Sun J (2013) Study on the designing rules and processability of porous structure based on selective laser melting (SLM). J Mater Process Technol 213: 1734-1742. https://doi.org/10.1016/j.jmatprotec.2013.05.001

82. Heinl P, Körner C, Singer RF (2008) Selective electron beam melting of cellular titanium: mechanical properties. Adv Eng Mater 10:882-888. https://doi.org/10.1002/adem.200800137

83. Hrabe NW, Heinl P, Flinn B, Körner C, Bordia RK (2011) Compression-compression fatigue of selective electron beam melted cellular titanium (Ti-6Al-4V). J Biomed Mater Res - Part B Appl Biomater 99(B):313-320. https://doi.org/10.1002/jbm.b. 31901

84. Li X, Feng Y-F, Wang C-T, Li G-C, Lei W, Zhang Z-Y, Wang L (2012) Evaluation of biological properties of electron beam melted Ti6Al4V implant with biomimetic coating in vitro and in vivo. PLoS One 7:e52049. https://doi.org/10.1371/journal.pone. 0052049

85. Karamooz Ravari MR, Nasr Esfahani S, Taheri Andani M, Kadkhodaei M, Ghaei A, Karaca H, Elahinia M (2016) On the effects of geometry, defects, and material asymmetry on the mechanical response of shape memory alloy cellular lattice structures. Smart Mater Struct 25. https://doi.org/10.1088/0964-1726/ $25 / 2 / 025008$
86. Han C, Yan C, Wen S, Xu T, Li S, Liu J, Wei Q, Shi Y (2017) Effects of the unit cell topology on the compression properties of porous co-Cr scaffolds fabricated via selective laser melting. Rapid Prototyp J 23:16-27. https://doi.org/10.1108/RPJ-082015-0114

87. Qiu C, Yue S, Adkins NJE, Ward M, Hassanin H, Lee PD, Withers PJ, Attallah MM (2015) Influence of processing conditions on strut structure and compressive properties of cellular lattice structures fabricated by selective laser melting. Mater Sci Eng A 628: 188-197. https://doi.org/10.1016/j.msea.2015.01.031

88. Gu H, Gong H, Pal D, Rafi K, Starr T, Stucker B (2013) Influences of energy density on porosity and microstructure of selective laser melted 17- 4PH stainless steel. Solid Free Fabr Proc 37:474- 489. https://doi.org/10.1007/s13398-014-0173-7.2

89. Aboulkhair NT, Everitt NM, Ashcroft I, Tuck C (2014) Reducing porosity in AlSi10Mg parts processed by selective laser melting. Addit Manuf 1:77-86. https://doi.org/10.1016/j.addma.2014.08. 001

90. Köhnen P, Haase C, Bültmann J, Ziegler S, Schleifenbaum JH, Bleck W (2018) Mechanical properties and deformation behavior of additively manufactured lattice structures of stainless steel. Mater Des 145:205-217. https://doi.org/10.1016/j.matdes.2018. 02.062

91. Wauthle R, Van Der Stok J, Yavari SA, Van Humbeeck J, Kruth JP, Zadpoor AA, Weinans H, Mulier M, Schrooten J (2015) Additively manufactured porous tantalum implants. Acta Biomater 14:217-225. https://doi.org/10.1016/j.actbio.2014.12. 003

92. Wauthle R, Ahmadi SM, Amin Yavari S, Mulier M, Zadpoor AA, Weinans H, Van Humbeeck J, Kruth JP, Schrooten J (2015) Revival of pure titanium for dynamically loaded porous implants using additive manufacturing. Mater Sci Eng C 54:94-100. https://doi.org/10.1016/j.msec.2015.05.001

93. Buchbinder D, Schleifenbaum H, Heidrich S, Meiners W, Bültmann J (2011) High power selective laser melting (HP SLM) of aluminum parts. Phys Procedia 12:271-278. https:// doi.org/10.1016/j.phpro.2011.03.035

94. Louvis E, Fox P, Sutcliffe CJ (2011) Selective laser melting of aluminium components. J Mater Process Technol 211:275-284. https://doi.org/10.1016/j.jmatprotec.2010.09.019

95. Amani Y, Dancette S, Delroisse P, Simar A, Maire E (2018) Compression behavior of lattice structures produced by selective laser melting: X-ray tomography based experimental and finite element approaches. Acta Mater 159:395-407. https://doi.org/ 10.1016/j.actamat.2018.08.030

96. Delroisse P, Jacques PJ, Maire E, Rigo O, Simar A (2017) Effect of strut orientation on the microstructure heterogeneities in AlSi10Mg lattices processed by selective laser melting. Scr Mater 141:32-35. https://doi.org/10.1016/j.scriptamat.2017.07. 020

97. Van Bael S, Kerckhofs G, Moesen M, Pyka G, Schrooten J, Kruth JP (2011) Micro-CT-based improvement of geometrical and mechanical controllability of selective laser melted Ti6Al4V porous structures. Mater Sci Eng A 528:7423-7431. https://doi.org/10. 1016/j.msea.2011.06.045

98. Van Bael S, Chai YC, Truscello S, Moesen M, Kerckhofs G, Van Oosterwyck H, Kruth JP, Schrooten J (2012) The effect of pore geometry on the in vitro biological behavior of human periosteumderived cells seeded on selective laser-melted Ti6Al4V bone scaffolds. Acta Biomater 8:2824-2834. https://doi.org/10.1016/j. actbio.2012.04.001

99. Hildebrand T, Rüegsegger P (2018) A new method for the modelindependent assessment of thickness in three-dimensional images. J Microsc 185:67-75. https://doi.org/10.1046/j.1365-2818.1997. 1340694.x 
100. Amin Yavari S, Wauthle R, Van Der Stok J, Riemslag AC, Janssen M, Mulier M, Kruth JP, Schrooten J, Weinans H, Zadpoor AA (2013) Fatigue behavior of porous biomaterials manufactured using selective laser melting. Mater Sci Eng C 33:4849-4858. https://doi.org/10.1016/j.msec.2013.08.006

101. Warnke PH, Sherry E, Becker ST, Wiltfang J (2009) Rapid prototyping: porous titanium alloy scaffolds produced by selective laser melting for bone tissue engineering. Tissue Eng Part C Methods 15:115-124. https://doi.org/10.1089/ten.tec.2008.0288

102. van Grunsven W, Hernandez-Nava E, Reilly G, Goodall R (2014) Fabrication and mechanical characterisation of titanium lattices with graded porosity. Metals (Basel) 4:401-409. https://doi.org/ $10.3390 /$ met4030401

103. Xiao L, Song W, Wang C, Tang H, Fan Q, Liu N, Wang J (2017) Mechanical properties of open-cell rhombic dodecahedron titanium alloy lattice structure manufactured using electron beam melting under dynamic loading. Int J Impact Eng 100:75-89. https:// doi.org/10.1016/j.ijimpeng.2016.10.006

104. Sing SL, Wiria FE, Yeong WY (2018) Selective laser melting of lattice structures: a statistical approach to manufacturability and mechanical behavior. Robot Comput Integr Manuf 49:170-180. https://doi.org/10.1016/j.rcim.2017.06.006

105. Yang L, Harrysson O, Cormier D, West H, Gong H, Stucker B (2015) Additive manufacturing of metal cellular structures: design and fabrication. JOM 67:608-615. https://doi.org/10.1007/ s11837-015-1322-y

106. Al-Saedi DSJ, Masood SH, Faizan-Ur-Rab M, Alomarah A, Ponnusamy P (2018) Mechanical properties and energy absorption capability of functionally graded F2BCC lattice fabricated by SLM. Mater Des 144:32-44. https://doi.org/10.1016/j.matdes. 2018.01.059

107. Li X, Wang C, Zhang W, Li Y (2009) Fabrication and characterization of porous Ti6Al4V parts for biomedical applications using electron beam melting process. Mater Lett 63:403-405. https:// doi.org/10.1016/j.matlet.2008.10.065

108. Wieding J, Jonitz A, Bader R (2012) The effect of structural design on mechanical properties and cellular response of additive manufactured titanium scaffolds. Materials (Basel) 5:1336-1347. https://doi.org/10.3390/ma5081336

109. de Formanoir C, Suard M, Dendievel R, Martin G, Godet S (2016) Improving the mechanical efficiency of electron beam melted titanium lattice structures by chemical etching. Addit Manuf 11:7176. https://doi.org/10.1016/j.addma.2016.05.001

110. Hernández-Nava E, Smith CJ, Derguti F, Tammas-Williams S, Leonard F, Withers PJ, Todd I, Goodall R (2016) The effect of defects on the mechanical response of Ti-6Al-4V cubic lattice structures fabricated by electron beam melting. Acta Mater 108: 279-292. https://doi.org/10.1016/j.actamat.2016.02.029

111. Amin Yavari S, Ahmadi SM, Wauthle R, Pouran B, Schrooten J, Weinans H, Zadpoor AA (2015) Relationship between unit cell type and porosity and the fatigue behavior of selective laser melted meta-biomaterials. J Mech Behav Biomed Mater 43:91-100. https://doi.org/10.1016/j.jmbbm.2014.12.015

112. Townsend A, Senin N, Blunt L, Leach RK, Taylor JS (2016) Surface texture metrology for metal additive manufacturing: a review. Precis Eng 46:34-47. https://doi.org/10.1016/j. precisioneng.2016.06.001

113. Carmignato S, Dewulf W, Leach RK (2017) Industrial X-ray computed tomography. Springer International Publishing

114. Ho ST, Hutmacher DW (2006) A comparison of micro CT with other techniques used in the characterization of scaffolds. Biomaterials 27:1362-1376. https://doi.org/10.1016/j. biomaterials.2005.08.035

115. Slotwinski JA, Garboczi EJ, Hebenstreit KM (2014) Porosity measurements and analysis for metal additive manufacturing process control. J Res Natl Inst Stand Technol 119:494-528. https://doi.org/10.6028/jres.119.019

116. Senin N, Thompson A, Leach RK (2018) Feature-based characterisation of signature topography in laser powder bed fusion of metals. Meas Sci Technol:29. https://doi.org/10.1088/1361-6501/ aa9e19

117. ISO (2012) BSI standards publication geometrical product specifications (GPS) - surface texture: areal. Part 2: terms, definitions and surface

118. Townsend A, Pagani L, Scott P, Blunt L (2017) Areal surface texture data extraction from X-ray computed tomography reconstructions of metal additively manufactured parts. Precis Eng 48:254-264. https://doi.org/10.1016/j.precisioneng.2016. 12.008

119. Thompson A, Senin N, Maskery I, Körner L, Lawes S, Leach RK (2018) Internal surface measurement of metal powder bed fusion parts. In: Addit Manuf https://doi.org/10.1016/j.addma.2018.01. 003. Accessed 5 Apr 2018

120. Newton L, Senin N, Gomez C, Danzl R, Helmli F, Blunt L, Leach RK (2019) Areal topography measurement of metal additive surfaces using focus variation microscopy. Addit Manuf 25:365-389. https://doi.org/10.1016/j.addma.2018.11.013

121. Mazur M, Leary M, Sun S, Vcelka M, Shidid D, Brandt M (2016) Deformation and failure behaviour of Ti-6Al-4V lattice structures manufactured by selective laser melting (SLM). Int J Adv Manuf Technol 84:1391-1411. https://doi.org/10.1007/s00170-0157655-4

122. Mazur M, Leary M, McMillan M, Elambasseril J, Brandt M (2016) SLM additive manufacture of $\mathrm{H} 13$ tool steel with conformal cooling and structural lattices. Rapid Prototyp J 22:504-518. https://doi.org/10.1108/RPJ-06-2014-0075

123. Cansizoglu O, Harrysson O, Cormier D, West H, Mahale T (2008) Properties of Ti-6Al-4V non-stochastic lattice structures fabricated via electron beam melting. Mater Sci Eng A 492:468-474. https://doi.org/10.1016/j.msea.2008.04.002

124. Bagheri ZS, Melancon D, Liu L, Johnston RB, Pasini D (2017) Compensation strategy to reduce geometry and mechanics mismatches in porous biomaterials built with selective laser melting. J Mech Behav Biomed Mater 70:17-27. https://doi.org/10.1016/j. jmbbm.2016.04.041

125. Xuanyong L, Chu PK, Ding C (2004) Surface modification of titanium, titanium alloys, and related materials for biomedical applications. Mater Sci Eng R Rep 47:49-121. https://doi.org/10. 1016/j.mser.2004.11.001

126. Lhuissier P, de Formanoir C, Martin G, Dendievel R, Godet S (2016) Geometrical control of lattice structures produced by EBM through chemical etching: investigations at the scale of individual struts. Mater Des 110:485-493. https://doi.org/10.1016/j. matdes.2016.08.029

127. Agarwala MK, Bourell DL, Beaman JJ (1994) Densification of selective laser sintered metal parts by hot isotatic pressing. Proc SFF Symp:65-73

128. Agarwala M, Bourell D, Beaman J, Marcus H, Barlow J (1995) Post-processing of selective laser sintered metal parts. Rapid Prototyp J 1:36-44. https://doi.org/10.1108/ 13552549510086853

129. Li P, Warner DH, Pegues JW, Roach MD, Shamsaei N, Phan N (2019) Investigation of the mechanisms by which hot isostatic pressing improves the fatigue performance of powder bed fused Ti-6Al-4V. Int J Fatigue 120:342-352. https://doi.org/10.1016/j. ijfatigue.2018.10.015

130. Wu MW, Chen JK, Lin BH, Chiang PH (2017) Improved fatigue endurance ratio of additive manufactured Ti-6Al-4V lattice by hot isostatic pressing. Mater Des 134:163-170. https://doi.org/10. 1016/j.matdes.2017.08.048 
131. Dutton B, Vesga W, Waller J, James S, Seifi M (2019) Metal additive manufacturing defect formation and NDE detectability. STP1620 ASTM Symp Struct Integr Addit Manuf Parts:1-36

132. Van Hooreweder B, Apers Y, Lietaert K, Kruth JP (2017) Improving the fatigue performance of porous metallic biomaterials produced by selective laser melting. Acta Biomater 47:193202. https://doi.org/10.1016/j.actbio.2016.10.005
133. Dong G, Tang Y, Zhao YF (2017) A survey of modeling of lattice structures fabricated by additive manufacturing. J Mech Des 139: 100906. https://doi.org/10.1115/1.4037305

Publisher's note Springer Nature remains neutral with regard to jurisdictional claims in published maps and institutional affiliations. 